\title{
Trends in temperature and rainfall extremes in the Yellow River source region, China
}

\author{
Yurong Hu • Shreedhar Maskey • Stefan Uhlenbrook
}

Received: 29 January 2010 / Accepted: 25 February 2011 / Published online: 24 March 2011

(C) Springer Science+Business Media B.V. 2011

\begin{abstract}
Spatial and temporal changes in daily temperature and rainfall indices are analyzed for the source region of Yellow River. Three periods are examined: 19601990, 1960-2000 and 1960-2006. Significant warming trends have been observed for the whole study region over all the three periods, particularly over the period 19602006. This warming is mainly attributed to a significant increase in the minimum temperature, and characterized by pronounced changes in the low temperature events composing a significant increase in the magnitude and a significant decrease in the frequency. In contrast to the temperature indices, no significant changes have been observed in the rainfall indices at the majority of stations. However, the rainfall shows noticeable increasing trends during winter and spring from a basin-wide point of view. Conversely, the frequency and contribution of moderately heavy rainfall events to total rainfall show a significant decreasing trend in summer. To conclude, this study shows that over the past 40-45 years the source region of the Yellow River has become warmer and experienced some seasonally varying changes in rainfall, which also supports an emerging global picture of warming and the prevailing positive trends in winter rainfall extremes over the mid-latitudinal land areas of the Northern Hemisphere.
\end{abstract}

Y. Hu (凶)

Yellow River Conservancy Commission, Zhengzhou 450003, People's Republic of China e-mail: y.hu@unesco-ihe.org

Y. Hu $\cdot$ S. Maskey $\cdot$ S. Uhlenbrook

UNESCO-IHE Institute for Water Education, PO Box 3015, 2601 DA, Delft, The Netherlands

S. Uhlenbrook

Department of Water Resources, Delft University of Technology,

PO Box 5048, 2600 GA, Delft, The Netherlands 


\section{Introduction}

In recent years, the frequent occurrence of extreme events, such as heat waves, heavy rain, hailstorm, snowfall, floods and droughts, have been reported worldwide (Ulbrich et al. 2003; Mirza 2003; Kundzewicz et al. 2005; Kyselý 2008). This raised special concerns that the potential changes in the extreme events could accompany global climate change. There is great interest in assessing changes in extreme events because of their strong impacts on both human society and the natural environment. A number of theoretical modelling and empirical analyses have suggested that notable changes in the frequency and intensity of extreme events, including floods, may occur even when there are only small changes in the mean climate (Katz and Brown 1992; Wagner 1996). Groisman et al. (2005) showed that on a global scale, changes in heavy rainfall tend to be larger than changes in mean rainfall totals, and that increases in rainfall extremes occurred in many regions where no change or even a decrease in rainfall was observed. Changes in temperature and rainfall extremes in the twentieth century have also been observed in many parts of the world including the United States (Michaels et al. 2004), Canada (Vincent and Mekis 2006), UK (Osborn et al. 2000), Central and Western Europe (Moberg and Jones 2005), Western Germany (Hundecha and Bardossy 2005), Switzerland (Schmidli and Frei 2005), Northeastern Iberian Peninsula (López-Moreno et al. 2009), Czech Republic (Kyselý 2008), Italy (Brunetti et al. 2000, 2001), northeast Spain (Ramos and Martinez-Cassanovas 2006), parts of Iran (Masih et al. 2010), China (Zhai et al. 1999; Zhai and Pan 2003), India (Sen Roy and Balling 2004), Mongolia (Nandintsetseg et al. 2007), Australia (Suppiah and Hennessy 1998; Haylock and Nicholls 2000), New Zealand (Salinger and Griffiths 2001), South Africa (Kruger 2006), and South East Asia and the South Pacific (Plummer et al. 1999; Manton et al. 2001). These studies, along with many others, are considered an important step towards knowledge of changes in climate extremes. Comparison between the results of various studies have demonstrated difference across region, with both increasing and decreasing or even no trends being reported. Possible reasons for lack of a clear picture of worldwide extreme events, e.g. regional climate variability, the different methods for trend-testing and the definition of the extreme events, are discussed in Wang et al. (2008). However, more importantly, these different findings suggest a large diversity in regional and global climate change interpretations, and imply that analyses of changes in extremes are important in the context of global climate change.

Over China, Zhai and Pan (2003) studied the changes in the frequency of extreme temperature events based on the daily surface air temperature data from about 200 stations from 1951-1999 in China. Their study showed a slightly decreasing trend in the number of hot days (over $35^{\circ} \mathrm{C}$ ) and the number of frost days (below $0^{\circ} \mathrm{C}$ ). Meanwhile, increasing trends were detected in the frequencies of warm days and warm nights, and decreasing trends were found in the frequencies of cool days and cool nights in China. Zhai et al. (2005) reported that rainfall indices showed mixed patterns of change, but significant increases in extreme rainfall have been found in western China, the mid-lower reaches of the Yangtze River, and parts of the southwestern and southern China coastal areas.

This study focuses on the source region of the Yellow River originating in the Tibetan Plateau. Located in mountainous areas, the study region is expected to 
be sensitive to global climate change since mountains in many parts of the world are very sensitive and susceptible to a changing climate in view of their complex orography and fragile ecosystem (Beniston et al. 1997; Beniston 2003). Previous studies indicated that the Tibetan Plateau is one of the most sensitive areas in terms of response to global climate change (Liu and Chen 2000; Tang et al. 2008) due to its earlier and larger warming trend in comparison to the Northern Hemisphere and the same latitudinal zone in the same period. Although many studies have been undertaken to investigate climatic changes in the Yellow River basin including its source region, most of them focused on changes in the mean values of climatic variables at monthly, seasonal and annual time scale. Assessments of extreme temperature and rainfall changes in the Yellow River reported in the literature are very limited. It is particularly true for the source region of the Yellow River. Furthermore, most of previous studies have concentrated on the second half of the twentieth century (1960-2000), and the recent years have been not included. For example, Fu et al. (2004) investigated the hydro-climatic trends of the Yellow River from the 1950s to 1998. They found that the river basin has become warmer, with a more significant increase in minimum temperature than in mean and maximum temperatures while the observed precipitation trend is not significant. (Yang et al. 2004) analyzed the annual precipitation, mean temperature, pan evaporation, and river discharge trends in the Yellow River basin from the 1950s to the 1990s. It was found that the annual precipitation showed a non-significant decreasing trend of $45 \mathrm{~mm}$ and the air temperature increased by $1.28^{\circ} \mathrm{C}$ over the past 50 years. Tang et al. (2008) analyzed the changes in the spatial patterns of climatic and vegetation condition in the Yellow River basin from 1960 to 2000 and found decreasing precipitation and increasing temperature in most parts of the Yellow River basin with the largest temperature increase in the Tibetan Plateau. Xu et al. (2007) investigated the long-term trends in major climatic variables in the Yellow River basin from 19602000. The results indicated that temperature has increased over the Yellow River basin especially during autumn and winter, while the precipitation has generally decreased in all the seasons except in winter which shows a slight increase. They also found that precipitation in the upstream region of the Yellow River did not exhibit a significant trend, whereas both the middle and downstream regions showed a clear negative trend. This is also confirmed by Wang et al. (2001) who found that the annual precipitation in the headwater area showed no noticeable decreasing tendency between the 1950s and the 1990s. But summer precipitation (from June to September) showed a tendency to decline. Zhao et al. (2007) reported that over the past 40 years the annual mean temperature has significantly increased by $0.8^{\circ} \mathrm{C}$ in the upper Yellow River Basin while annual precipitation slightly decreased by $43 \mathrm{~mm}$. Zhang et al. (2008) recently published work on winter extreme low temperature events and summer extreme high-temperature events in the whole Yellow River for the period 1960-2004. They found that the whole Yellow River basin is dominated by the significant downward trend of frequency of the cold events and that significant upward trend of frequency and intensity of the high temperature events has been found in the western and northern part of the Yellow River basin.

As discussed earlier, most previous studies regarding climatic trends were based on the mean values of climatic variables. Although Zhang et al. (2008) studied the temperature extremes of the Yellow River for 1960-2004, they did not consider changes in rainfall extremes and in other important seasons such as spring (March- 
May) and autumn (September-November) in their study. The need for involving spring and autumn into studies of changes in climatic variables was highlighted by Kyselý (2008) since the differences in climatic variables exists not only between winter and summer but also between the transition seasons (spring and autumn). In this study, we use daily temperature and rainfall data for the period 1960-2006 to study the spatial and temporal changes in various indices for rainfall and temperature extremes in the source region of the Yellow River. Our study complements previous work by including a longer time series of data and more climatic extreme variables in the analysis. Furthermore, we include annual as well as four seasonal analyses, whereas Zhang et al. (2008) only considered winter and summer. Therefore, to the best of our knowledge this paper is the first most comprehensive regional analysis of trends in indices of rainfall and temperature extremes for the Yellow River source region over the second half of twentieth century based on historical climate observations. Although the main aim of the present study is to investigate trends in temperature and rainfall extremes in the Yellow River source region on both annual and seasonal basis, changes in the average climatic indexes are also assessed.

\section{Study area}

The Yellow River source region is generally defined as the upstream catchment above the Tangnag Hydrological Station, situated between $95^{\circ} 50^{\prime} 45^{\prime \prime} \mathrm{E}$ and $103^{\circ} 28^{\prime} 11^{\prime \prime} \mathrm{E}$ and $32^{\circ} 12^{\prime} 11^{\prime \prime} \mathrm{N}$ and $35^{\circ} 48^{\prime} 7^{\prime \prime} \mathrm{N}$ in the northeast Qinghai-Tibetan Plateau (Fig. 1). It covers an area of $121,972 \mathrm{~km}^{2}(15 \%$ of the whole Yellow River basin), and yields an annual average runoff of $168 \mathrm{~mm} / \mathrm{a}$ (35\% of the total runoff of Yellow River). Therefore, it is called "water tower" of the Yellow River. The altitude decreases from west to east with the highest elevation of $6282 \mathrm{~m}$ in the A'nyêmaqên Mountains and the lowest one of $2546 \mathrm{~m}$ in the village of Tangnag. There are large areas covered with lakes, swamps and grassland in the region. In addition, this region is a relatively pristine area and has been subject to few human interventions, e.g. neither large dam nor large irrigation project exist in this area, in comparison to the lower and middle Yellow River (Zheng et al. 2007; Sato et al. 2008).

Climatically, the source area of the Yellow River is cold, semi-humid characterized by the typical Qinghai-Tibetan Plateau climate system. In the cold season, its climate has the characteristics of typical continental climate, which is controlled by the high pressure of the Qinghai-Tibetan Plateau lasting for about 7 months. During the warm season it is affected by southwest monsoon, producing heat low pressure with abundant water vapor and a lot of rainfall and thus forms the Plateau sub-tropical humid monsoon climate. Annual basin averaged daily temperature varies between $-4^{\circ} \mathrm{C}$ and $2^{\circ} \mathrm{C}$ from the southeast to the northeast. July is the warmest month, with a mean daily temperature of $8^{\circ} \mathrm{C}$, whereas from October to April the temperature remains well below $0^{\circ} \mathrm{C}$.

The average annual rainfall is about $530 \mathrm{~mm} / \mathrm{a}$. More than $75 \%$ of the total annual rainfall falls in the wet season (June to September) caused by the southwest monsoon from the Bay of Bengal. Rainfall tends to decrease from the southeast $(\sim 800 \mathrm{~mm} / \mathrm{a})$ to the northwest $(\sim 200 \mathrm{~mm} / \mathrm{a})$. The rainfall in this region is generally of low intensity $(<50 \mathrm{~mm} / \mathrm{d})$, long duration (10-30 days) and covering large areas $\left(>100,000 \mathrm{~km}^{2}\right)$. The annual potential evaporation varies from $800-1200 \mathrm{~mm} / \mathrm{a}$ (Zheng et al. 2007). 


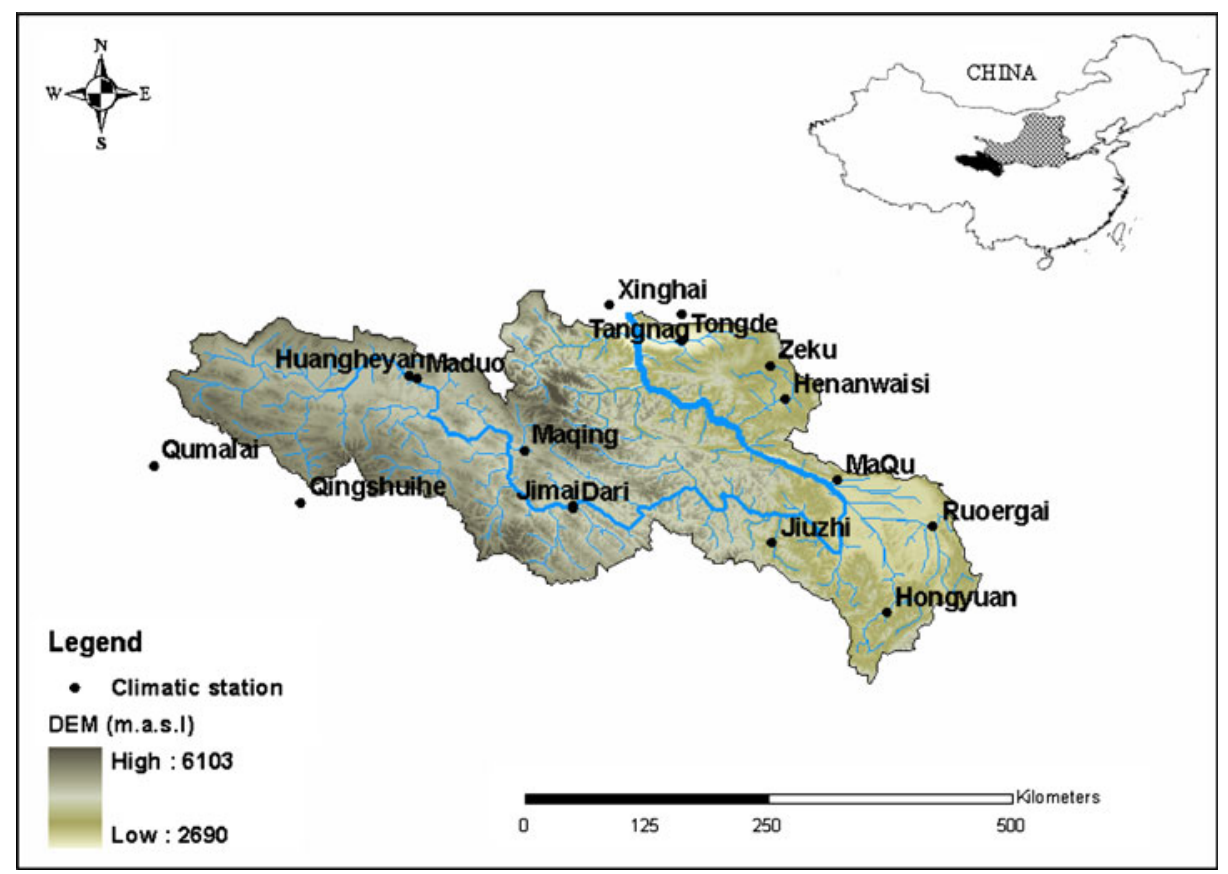

Fig. 1 Location of the study region and climatic station

There are permanent snow packs/covers and glaciers in the southern A'nyêmaqên, Bayankala and the northern Qilian Mountains.

\section{Methods}

\subsection{Data base}

Daily rainfall totals measured at 14 stations and daily maximum and minimum temperature at 13 stations (Table 1, Fig. 1) operated mostly by Yellow River Conservancy Commission and China Meteorological Administration are used. The observations span the period 1960-2006 and 1961-2006 for rainfall and temperature, respectively. The available series lengths range from 30 to 47 years. In order to seek a more spatial coverage in this data sparse mountainous region and make comparisons between different periods, data were analyzed for three different periods. The duration of the periods analyzed were 31 years, 41 years and 47 years for rainfall as well as 30 years, 40 years and 46 years for temperature with each period starting in 1960 for rainfall and 1961 for temperature.

\subsection{Data quality control}

The objective of data quality control was to identify questionable records in the climate datasets. Several types of quality controls were applied to the series of 
Table 1 Station list

\begin{tabular}{lclll}
\hline Station name & Longitude $\left({ }^{\circ} \mathrm{E}\right)$ & Latitude $\left({ }^{\circ} \mathrm{N}\right)$ & Altitude $(\mathrm{m})$ & Data type \\
\hline Huangheyan & 98.13 & 34.95 & 4,221 & Rainfall \\
Maduo & 98.22 & 34.92 & 4,273 & Rainfall, temperature \\
Jimai & 99.65 & 33.77 & 3,969 & Rainfall \\
Tangnag & 100.65 & 35.50 & 2,546 & Rainfall \\
Xinghai & 99.98 & 35.58 & 3,323 & Rainfall, temperature \\
Dari & 99.65 & 33.75 & 3,969 & Rainfall, temperature \\
Jiuzhi & 101.48 & 33.43 & 3,628 & Rainfall, temperature \\
MaQu & 102.08 & 34.00 & 3,472 & Rainfall, temperature \\
Ruoergai & 102.97 & 33.58 & 3,441 & Rainfall, temperature \\
Hongyuan & 102.55 & 32.80 & 3,491 & Rainfall, temperature \\
Tongde & 100.65 & 35.27 & 3,289 & Rainfall, temperature \\
Qumalai & 95.78 & 34.13 & 4,231 & Temperature \\
Henanwaisi & 101.60 & 34.73 & 3,500 & Rainfall, temperature \\
Zeku & 101.47 & 35.03 & 3,663 & Rainfall, temperature \\
Maqing & 99.20 & 34.27 & 4,211 & Rainfall, temperature \\
Qingshuihe & 97.13 & 33.80 & 4,418 & Temperature \\
\hline
\end{tabular}

daily rainfall, daily maximum temperature (Tmax) and daily minimum temperature (Tmin). First, the daily time series from each station were plotted and compared with neighboring stations for identifying outliers and missing data. Second, a revision of internal consistency was made, verifying that daily Tmax always exceeds daily Tmin. Third, annual mean series (annual total for rainfall) were produced from the daily rainfall and maximum and minimum temperature time-series, and examined for homogeneities using the double mass curve method, particularly to check if there are clear indications of relocation of the stations and/or change of instrumentation or observational practices.

Data gaps found in the time series were very minimal: $0.029 \%$ and $0.0017 \%$ of daily records for rainfall and temperature, respectively. The missing data values were filled up by their neighboring stations with the simple linear regressions, and the outliers were corrected with the data from the nearest stations or from the neighboring days. Results of the double mass curves of all stations demonstrated almost a straight line, thus no obvious breakpoints were detected in the time series of temperature and precipitation.

\subsection{Indices for characterizing temperature and rainfall extremes}

The indices chosen to evaluate changes in the rainfall and temperature patterns are able to represent a wide variety of rainfall and temperature characteristics for both the average regime and the extreme behavior of the rainfall and temperature processes. We selected 15 indices describing different aspects of the rainfall and temperature regimes. Many of them have been used in previous studies (Moberg and Jones 2005; López-Moreno et al. 2009) and recommended by the STARDEX project (Haylock and Goodess 2004). Table 2 provides the acronyms and short definitions of the selected indices. Values of each index were calculated on an annual basis and for four seasons: December to February (DJF), March to May (MAM), June to August (JJA) and September to November (SON). The STARDEX extremes 
Table 2 Investigated indices of daily precipitation and temperature

\begin{tabular}{lll}
\hline Acronym & Explanation & Units \\
\hline Precipitation related indices & $\mathrm{mm}$ \\
$P$ & Total rainfall & $\mathrm{d}$ \\
Pxcdd & Maximum number of consecutive days with precipitation $<1 \mathrm{~mm}$ & $\mathrm{~d}$ \\
Pxcwd & Maximum number of consecutive days with precipitation $>1 \mathrm{~mm}$ & $\mathrm{~d}$ \\
Pnl90 & Number of events exceeding the long-term 90th percentile of & \\
& precipitation & $\%$ \\
Pfl90 & Fraction of total precipitation from events $>$ long-term $90 \mathrm{th}$ & \\
& percentile of precipitation & $\mathrm{mm} / \mathrm{d}$ \\
Pint & Mean precipitation on wet days (days with precipitation $>1 \mathrm{~mm})$ & $\mathrm{mm}$ \\
Px5d & Maximum total precipitation from any consecutive 5 days & \\
Temperature related indices & ${ }^{\circ} \mathrm{C}$ \\
Txav & Mean of daily maximum temperature & ${ }^{\circ} \mathrm{C}$ \\
Tnav & Mean of daily minimum temperature & ${ }^{\circ} \mathrm{C}$ \\
Trav & Mean of daily diurnal temperature range & ${ }^{\circ} \mathrm{C}$ \\
Txq90 & 90th percentile of daily maximum temperature (hot days) & \\
Tnq10 & 10th percentile of daily minimum temperature (cold nights) & ${ }^{\circ} \mathrm{C}$ \\
Tnfd & Number of frost days Tmin $<0{ }^{\circ} \mathrm{C}$ & $\mathrm{d}$ \\
Txf90 & $\%$ days Tmax $>$ long term mean 90th percentile & $\%$ \\
Tnfl0 & \% days Tmin $<$ long term mean 10th percentile & $\%$ \\
\hline
\end{tabular}

indices software is available at http:/www.cru.uea.ac.uk/cru/projects/stardex/ and was used for calculating all these indices in this study.

\subsection{Trend estimation}

A trend analysis was performed on the time series of the 15 indices using the nonparametric Mann-Kendall (MK) statistical test (Mann 1945; Kendall 1975). This test allows us to investigate long-term trends of data without assuming any particular distribution. Moreover, it is less influenced by outliers in the data set as it is nonparametric. Statistical significance of the trends is evaluated at the $10 \%$ level of significance against the null hypothesis that there is no trend in the analyzed variable. The test statistic $S$ of the MK test is defined as follows:

$$
\begin{gathered}
S=\sum_{i=1}^{n-1} \sum_{j=i+1}^{n} \operatorname{sgn}\left(x_{j}-x_{i}\right) \\
\operatorname{sgn}\left(x_{j}-x_{i}\right)=\left\{\begin{array}{cc}
+1 & x_{j}>x_{i} \\
0, & x_{j}=x_{i} \\
-1, & x_{j}<x_{i}
\end{array}\right\}
\end{gathered}
$$

where $n$ is the data record length, $x_{i}$ and $x_{j}$ are the sequential data values. For $n \geq 10$, the test statistic $S$ is approximately normally distributed with the mean and variance given by

$$
E[\mathrm{~S}]=0
$$




$$
\operatorname{Var}(S)=\frac{n(n-1)(2 n+5)-\sum_{i=1}^{m} t_{i}\left(t_{i}-1\right)\left(2 t_{i}+5\right)}{18}
$$

where $m$ is the number of tied groups and $t_{i}$ is the size of the $i^{\text {th }}$ tied group. The standardized test statistics $Z$ is computed by

$$
Z=\left\{\begin{array}{c}
\frac{S-1}{\sqrt{\operatorname{Var}(S)}} S>0 \\
0 \quad S=0 \\
\frac{S+1}{\sqrt{\operatorname{Var}(S)}} S<0
\end{array}\right.
$$

The standardized MK test statistics $Z$ follows the standard normal distribution with a mean of zero and variance of one under the null hypothesis of no trend. If $|Z|>$ $Z_{1-\alpha / 2}$, the null hypothesis is rejected at $\alpha$ level of significance. A positive value of $Z$ indicates an upward trend and whereas a negative value indicates a downward trend.

\subsubsection{Serial correlation}

The Mann-Kendall approach requires the data to be serially independent (von Storch and Navarra 1995). The presence of serial correlation in the analyzed time series can have serious impacts on the results of a trend test. A positive serial correlation can overestimate the probability of a trend and a negative correlation may cause its underestimation. In this study, Mann-Kendall test was used in conjunction with the widely used method of pre-whitening. The pre-whitening removes serial correlation from the data by means of the following formula:

$$
y_{t}=x_{t}-\phi x_{t-1}
$$

where $y_{t}$ is the pre-whitened time series value, $x_{t}$ is the original time series value for time interval $t$, and $\phi$ is the lag 1 autocorrelation coefficient.

In this study, the pre-whitening was applied when a serial dependence was found significant at the $5 \%$ level. In our case, most of the studied variables did not show significant serial correlation except the annual mean minimum temperature series at Henan, Hongyuan, Xinghai, Jiuzhi and Zeku stations. Before applying the trend test, the pre-whitening was applied to remove serial correlation from these time series.

\subsubsection{Theil and Sen's median slope estimator}

The Theil-Sen estimator is used to estimate the slope of linear trends (Sen 1968). The estimator is also termed 'median of pair-wise slopes'. It is frequently applied in climatological practice (e.g. Kunkel et al. 1999; Zhang et al. 2001) and outperforms the least-squares regression in computing the magnitude of linear trends when the sample size is large (Zhang et al. 2004).

The slope estimates of $N$ pairs of data are first computed by

$$
Q_{i}=\frac{x_{j}-x_{k}}{j-k} \quad \text { For } i=1, \ldots N
$$

where $x_{j}$ and $x_{k}$ are data values at times $j$ and $k(j>k)$, respectively. The median of these $N$ values of $Q_{i}$ is the Sen's estimator of slope. 


\section{Results}

The results of the Mann-Kendall test are summarized in Table 3 for temperature and in Table 4 for rainfall. Presented is the percentage of stations with significant negative trend, significant positive trend and no trend or insignificant trend for each of the indices and for the three study periods. The spatial patterns of the temperature

Table 3 Percentage of stations with significant negative trend $(-)$, significant positive trend $(+)$ and no trend or insignificant trend (0) in temperature indices at the $10 \%$ level

\begin{tabular}{|c|c|c|c|c|c|c|c|c|c|c|}
\hline \multirow[t]{2}{*}{ Season } & \multirow[t]{2}{*}{ Indices } & \multicolumn{3}{|c|}{ 1960-1990 (13 stations) } & \multicolumn{3}{|c|}{ 1960-2000 (12 stations) } & \multicolumn{3}{|c|}{ 1960-2006 (10 stations) } \\
\hline & & - & 0 & + & - & 0 & + & - & 0 & + \\
\hline \multirow[t]{8}{*}{$\mathrm{DJF}$} & Txav & 0 & 100 & 0 & 8.3 & 91.7 & 0 & 0 & 70 & 30 \\
\hline & Tnav & 0 & 23.1 & 76.9 & 8.3 & 25 & 66.7 & 10 & 10 & 80 \\
\hline & Trav & 53.8 & 46.2 & 0 & 58.3 & 25 & 16.7 & 60 & 20 & 20 \\
\hline & Tnfd & 0 & 100 & 0 & 0 & 100 & 0 & 0 & 100 & 0 \\
\hline & Txq90 & 0 & 76.9 & 23.1 & 0 & 75 & 25 & 0 & 60 & 40 \\
\hline & Tnq10 & 0 & 46.2 & 53.8 & 16.7 & 25 & 58.3 & 10 & 20 & 70 \\
\hline & $T x f 90$ & 0 & 69.2 & 30.8 & 0 & 75 & 25 & 0 & 60 & 40 \\
\hline & Tnf10 & 76.9 & 23.1 & 0 & 58.3 & 33.4 & 8.3 & 70 & 20 & 10 \\
\hline \multirow[t]{8}{*}{ MAM } & Txav & 30.8 & 69.2 & 0 & 8.3 & 83.4 & 8.3 & 10 & 80 & 10 \\
\hline & Tnav & 0 & 46.2 & 53.8 & 8.3 & 22.5 & 69.2 & 10 & 10 & 80 \\
\hline & Trav & 76.9 & 23.1 & 0 & 75 & 16.7 & 8.3 & 70 & 20 & 10 \\
\hline & Tnfd & 0 & 92.3 & 7.7 & 16.7 & 75 & 8.3 & 20 & 70 & 10 \\
\hline & Txq90 & 0 & 100 & 0 & 8.3 & 83.4 & 8.3 & 10 & 90 & 0 \\
\hline & Tnq10 & 0 & 53.8 & 46.2 & 0 & 33.3 & 66.7 & 10 & 20 & 70 \\
\hline & Txf 90 & 7.7 & 92.3 & 0 & 8.3 & 91.7 & 0 & 10 & 90 & 0 \\
\hline & Tnf10 & 53.8 & 46.2 & 0 & 66.7 & 25 & 8.3 & 70 & 20 & 10 \\
\hline \multirow[t]{8}{*}{ JJA } & Txav & 0 & 100 & 0 & 0 & 75 & 25 & 0 & 40 & 60 \\
\hline & Tnav & 0 & 69.2 & 30.8 & 8.3 & 33.4 & 58.3 & 0 & 20 & 80 \\
\hline & Trav & 23.1 & 76.9 & 0 & 16.7 & 83.3 & 0 & 20 & 80 & 0 \\
\hline & Tnfd & 38.5 & 61.5 & 0 & 58.3 & 33.4 & 8.3 & 80 & 10 & 10 \\
\hline & Txq90 & 0 & 100 & 0 & 0 & 75 & 25 & 0 & 30 & 70 \\
\hline & Tnq10 & 0 & 46.2 & 53.8 & 16.7 & 16.6 & 66.7 & 0 & 30 & 70 \\
\hline & $T x f 90$ & 0 & 100 & 0 & 0 & 66.7 & 33.3 & 0 & 30 & 70 \\
\hline & Tnf10 & 46.2 & 46.1 & 7.7 & 66.7 & 16.6 & 16.7 & 60 & 40 & 0 \\
\hline \multirow[t]{8}{*}{ SON } & Txav & 7.7 & 92.3 & 0 & 8.3 & 66.7 & 25 & 0 & 20 & 80 \\
\hline & Tnav & 7.7 & 61.5 & 30.8 & 8.3 & 41.7 & 50 & 10 & 30 & 60 \\
\hline & Trav & 0 & 100 & 0 & 8.3 & 83.4 & 8.3 & 10 & 70 & 20 \\
\hline & Tnfd & 0 & 92.3 & 7.7 & 0 & 91.7 & 8.3 & 10 & 80 & 10 \\
\hline & Txq90 & 7.1 & 92.9 & 0 & 0 & 100 & 0 & 0 & 90 & 10 \\
\hline & Tnq10 & 7.7 & 46.1 & 46.2 & 8.3 & 41.7 & 50 & 10 & 20 & 70 \\
\hline & $\operatorname{Txf} 90$ & 7.7 & 92.3 & 0 & 0 & 91.7 & 8.3 & 0 & 60 & 40 \\
\hline & Tnf10 & 38.5 & 53.8 & 7.7 & 66.7 & 25 & 8.3 & 60 & 30 & 10 \\
\hline \multirow[t]{8}{*}{ Annual } & Txav & 7.7 & 92.3 & 0 & 8.3 & 75 & 16.7 & 10 & 40 & 50 \\
\hline & Tnav & 7.7 & 23.1 & 69.2 & 8.3 & 25 & 66.7 & 10 & 10 & 80 \\
\hline & Trav & 61.5 & 38.5 & 0 & 58.3 & 25 & 16.7 & 60 & 10 & 30 \\
\hline & Tnfd & 23.1 & 69.2 & 7.7 & 33.3 & 58.4 & 8.3 & 70 & 20 & 10 \\
\hline & Txq90 & 7.7 & 92.3 & 0 & 8.3 & 91.7 & 0 & 0 & 60 & 40 \\
\hline & Tnq10 & 0 & 46.2 & 53.8 & 8.3 & 33.4 & 58.3 & 10 & 20 & 70 \\
\hline & $T x f 90$ & 0 & 92.3 & 7.7 & 0 & 83.3 & 16.7 & 0 & 30 & 70 \\
\hline & Tnf10 & 61.5 & 30.8 & 7.7 & 66.7 & 25 & 8.3 & 80 & 10 & 10 \\
\hline
\end{tabular}


Table 4 Percentage of stations with significant negative trend $(-)$, significant positive trend $(+)$ and no trend or insignificant trend (0) in rainfall indices at the $10 \%$ level

\begin{tabular}{|c|c|c|c|c|c|c|c|c|c|c|}
\hline \multirow[t]{2}{*}{ Season } & \multirow[t]{2}{*}{ Indices } & \multicolumn{3}{|c|}{ 1960-1990 (14 stations) } & \multicolumn{3}{|c|}{ 1960-2000 (10 stations) } & \multicolumn{3}{|c|}{ 1960-2006 (7 stations) } \\
\hline & & - & 0 & + & $\overline{-}$ & 0 & + & - & 0 & + \\
\hline \multirow[t]{7}{*}{ DJF } & $P x 5 d$ & 0 & 85.7 & 14.3 & 0 & 90 & 10 & 0 & 100 & 0 \\
\hline & Pxcdd & 7.1 & 92.9 & 0 & 30 & 70 & 0 & 28.6 & 71.4 & 0 \\
\hline & Pxcwd & 0 & 100 & 0 & 0 & 90 & 10 & 0 & 100 & 0 \\
\hline & Pint & 0 & 100 & 0 & 0 & 100 & 0 & 0 & 100 & 0 \\
\hline & Pfl90 & 0 & 92.9 & 7.1 & 0 & 90 & 10 & 0 & 100 & 0 \\
\hline & Pnl90 & 0 & 92.9 & 7.1 & 0 & 80 & 20 & 0 & 100 & 0 \\
\hline & $P$ & 0 & 71.4 & 28.6 & 0 & 70 & 30 & 0 & 71.4 & 28.6 \\
\hline \multirow[t]{7}{*}{ MAM } & $P x 5 d$ & 0 & 100 & 0 & 0 & 100 & 0 & 0 & 100 & 0 \\
\hline & Pxcdd & 7.1 & 92.9 & 0 & 10 & 90 & 0 & 0 & 100 & 0 \\
\hline & Pxcwd & 0 & 100 & 0 & 0 & 100 & 0 & 0 & 100 & 0 \\
\hline & Pint & 0 & 100 & 0 & 0 & 100 & 0 & 0 & 85.7 & 14.3 \\
\hline & Pfl90 & 0 & 100 & 0 & 0 & 100 & 0 & 14.3 & 85.7 & 0 \\
\hline & Pnl90 & 0 & 100 & 0 & 0 & 90 & 10 & 0 & 100 & 0 \\
\hline & $P$ & 0 & 92.9 & 7.1 & 0 & 80 & 20 & 0 & 71.4 & 28.6 \\
\hline \multirow[t]{7}{*}{ JJA } & $P x 5 d$ & 0 & 100 & 0 & 0 & 90 & 10 & 0 & 100 & 0 \\
\hline & Pxcdd & 0 & 100 & 0 & 0 & 100 & 0 & 0 & 100 & 0 \\
\hline & Pxcwd & 0 & 100 & 0 & 0 & 100 & 0 & 14.3 & 85.7 & 0 \\
\hline & Pint & 0 & 100 & 0 & 0 & 100 & 0 & 0 & 100 & 0 \\
\hline & Pfl90 & 0 & 100 & 0 & 0 & 100 & 0 & 0 & 100 & 0 \\
\hline & Pnl90 & 0 & 100 & 0 & 0 & 100 & 0 & 0 & 100 & 0 \\
\hline & $P$ & 0 & 100 & 0 & 0 & 100 & 0 & 0 & 100 & 0 \\
\hline \multirow[t]{7}{*}{ SON } & $P x 5 d$ & 0 & 100 & 0 & 20 & 80 & 0 & 0 & 100 & 0 \\
\hline & Pxcdd & 0 & 85.7 & 14.3 & 0 & 70 & 30 & 0 & 100 & 0 \\
\hline & Pxcwd & 7.1 & 92.9 & 0 & 10 & 90 & 0 & 0 & 100 & 0 \\
\hline & Pint & 0 & 100 & 0 & 0 & 100 & 0 & 0 & 100 & 0 \\
\hline & Pfl90 & 7.1 & 92.9 & 0 & 10 & 90 & 0 & 0 & 100 & 0 \\
\hline & Pnl90 & 0 & 100 & 0 & 20 & 80 & 0 & 0 & 100 & 0 \\
\hline & $P$ & 0 & 100 & 0 & 20 & 80 & 0 & 14.3 & 85.7 & 0 \\
\hline \multirow[t]{7}{*}{ Annual } & $P x 5 d$ & 0 & 100 & 0 & 0 & 100 & 0 & 0 & 100 & 0 \\
\hline & Pxcdd & 0 & 100 & 0 & 0 & 100 & 0 & 14.3 & 85.7 & 0 \\
\hline & Pxcwd & 0 & 100 & 0 & 10 & 90 & 0 & 0 & 100 & 0 \\
\hline & Pint & 0 & 100 & 0 & 0 & 100 & 0 & 0 & 100 & 0 \\
\hline & Pfl9o & 0 & 100 & 0 & 10 & 90 & 0 & 0 & 100 & 0 \\
\hline & Pnl90 & 0 & 100 & 0 & 0 & 100 & 0 & 0 & 100 & 0 \\
\hline & $P$ & 0 & 100 & 0 & 10 & 80 & 10 & 0 & 85.7 & 14.3 \\
\hline
\end{tabular}

indices are displayed for the longer period 1961-2006 while for rainfall it is done for the period 1960-2000 in order to seek a balance between the spatial coverage and the observations period length. Figure 2 shows the trend sign and the change per decade for the eight annual temperature indices. Figures 3, 4, 5, 6 present similar data as in Fig. 2, but for winter, spring, summer and autumn, respectively. A similar order presents the results for the rainfall (Figs. 7, 8, 9, 10, 11).

\subsection{Temperature}

Overall, significant trends dominate in all the temperature indices for the three different periods. Trends in the longer period 1961-2006 are more pronounced 
Txav $\left({ }^{\circ} \mathrm{C}\right)$

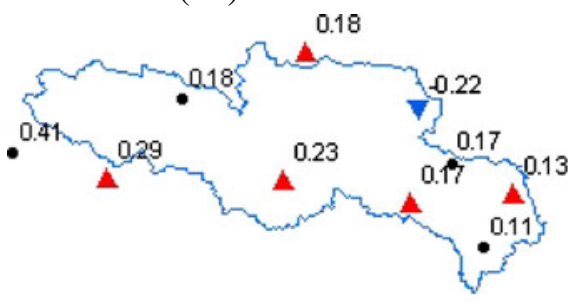

$\operatorname{Trav}\left({ }^{\circ} \mathrm{C}\right)$

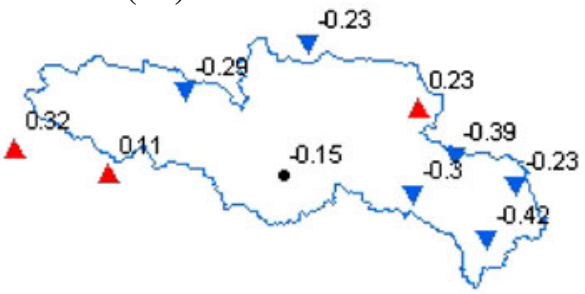

$\operatorname{Txq} 90\left({ }^{\circ} \mathrm{C}\right)$

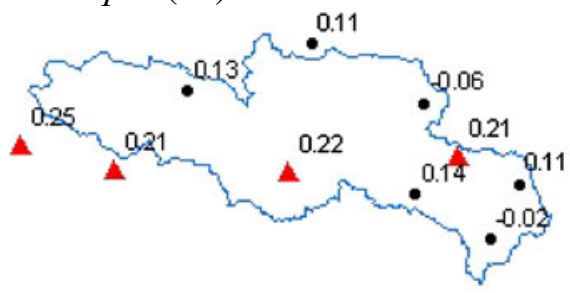

$\operatorname{Txf} 90(\%)$

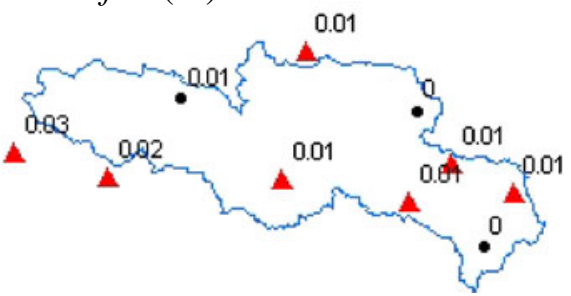

$\operatorname{Tnav}\left({ }^{\circ} \mathrm{C}\right)$

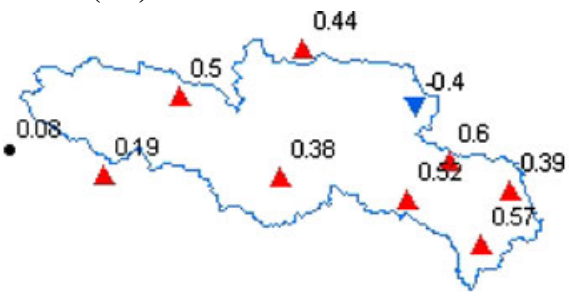

$\operatorname{Tnfd}(\mathrm{d})$

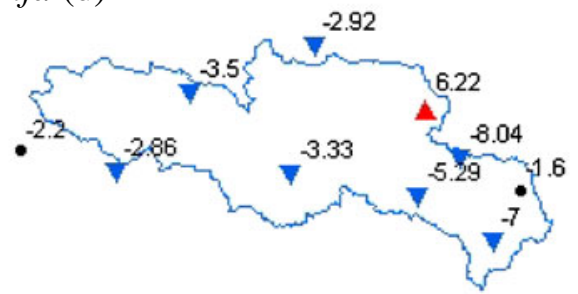

$\operatorname{Tnq} 10\left({ }^{\circ} \mathrm{C}\right)$

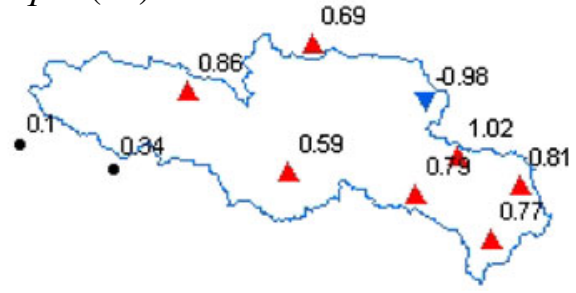

$\operatorname{Tnf10}(\%)$

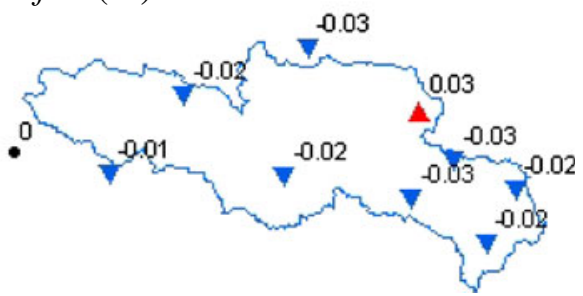

Fig. 2 Signs of trends and change per decade for the eight annual temperature indices in the study area for the period 1961-2006. Significant increasing (decreasing) trends are marked by filled triangles (filled upright triangle, filled inverse triangle). Insignificant trends are marked by small dots (filled circle)

and frequent than in the two shorter periods (1961-1990 and 1961-2000). This behaviour is consistent with the greater power of the trend test for longer analysis periods.

In the period 1961-2006, significant increasing trends dominate in mean daily maximum temperature (Txav) on an annual basis with $50 \%$ of the stations showing 
$\operatorname{Txav}\left({ }^{\circ} \mathrm{C}\right)$

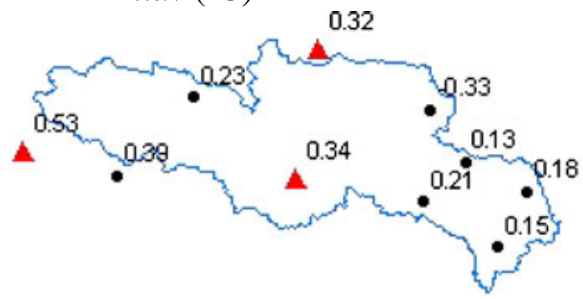

$\operatorname{Trav}\left({ }^{\circ} \mathrm{C}\right)$
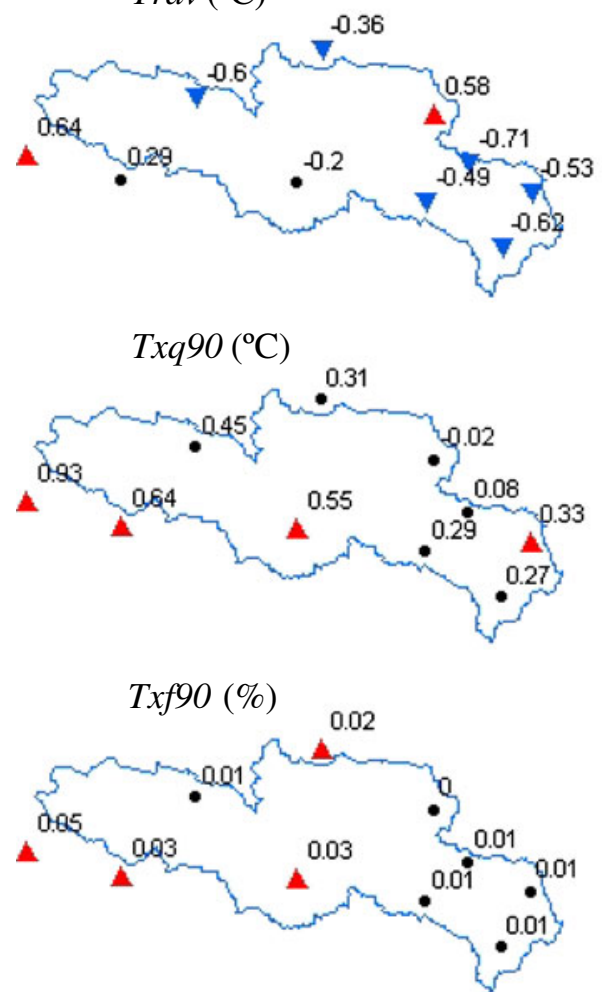

Thav $\left({ }^{\circ} \mathrm{C}\right)$

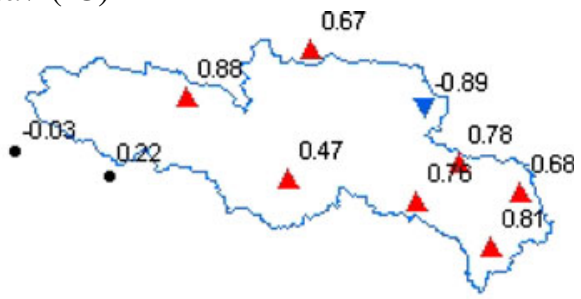

$\operatorname{Tnfd}(\mathrm{d})$

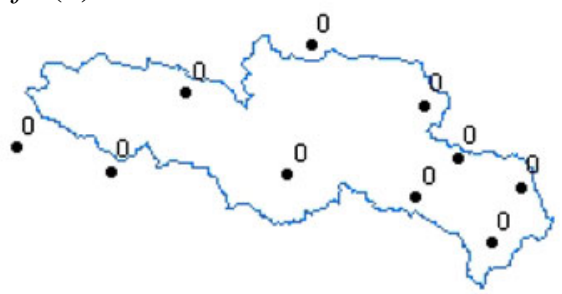

$\operatorname{Tn} q 10\left({ }^{\circ} \mathrm{C}\right)$

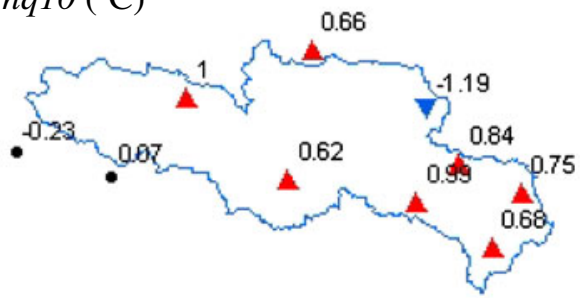

$\operatorname{Tnf10}(\%)$

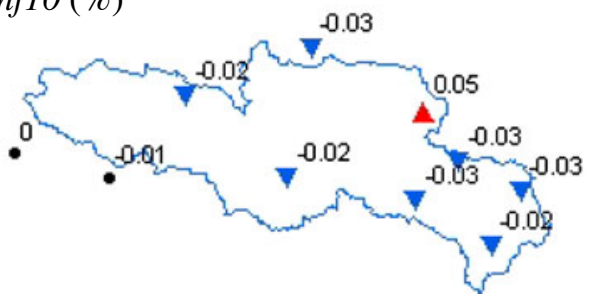

Fig. 3 Same as in Fig. 2, but for winter

significant positive trends, whereas few stations show an increasing trend in the two shorter periods. On a seasonal basis, Txav shows the largest warming trends in autumn with $80 \%$ of the stations having a significant positive trend while only $25 \%$ show a significant positive trend in the period 1961-2000 and no station shows a significant positive trend in the period 1961-1990. Similarly, significant warming trends also dominate in summer with $60 \%$ of the stations having significant positive trends in the period 1961-2006 while there are few or even no stations with significant positive trends in two shorter periods. In winter, $30 \%$ of the stations show a significant positive trend in the period 1961-2006 while almost all stations show no significant trend for the two short periods. The mean daily minimum temperature 
$\operatorname{Txav}\left({ }^{\circ} \mathrm{C}\right)$

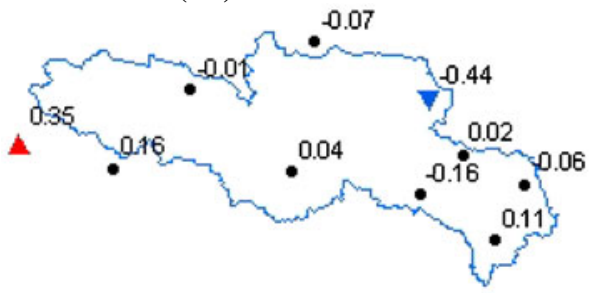

$\operatorname{Trav}\left({ }^{\circ} \mathrm{C}\right)$
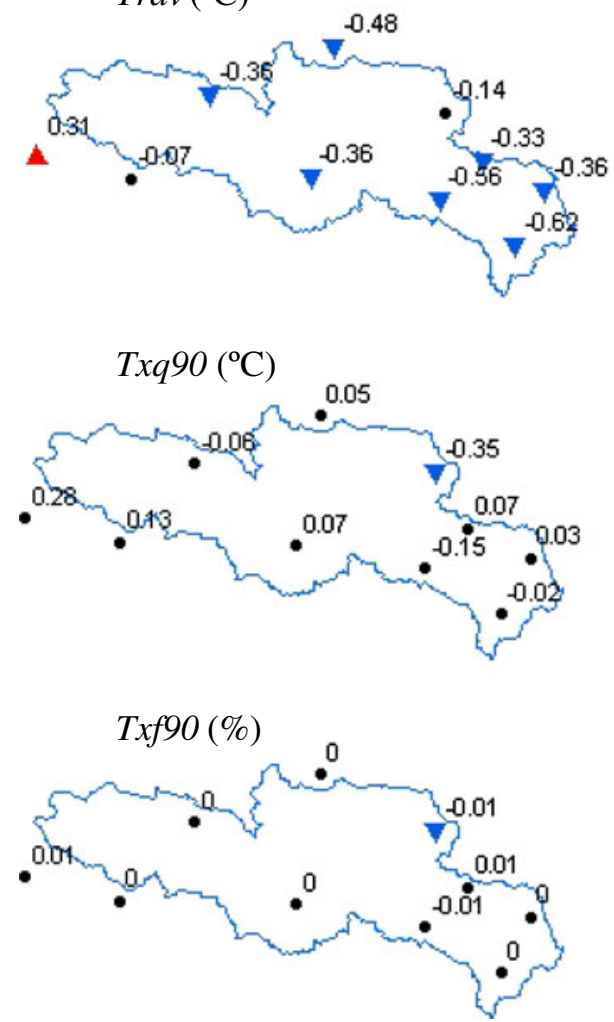

$\operatorname{Tnav}\left({ }^{\circ} \mathrm{C}\right)$

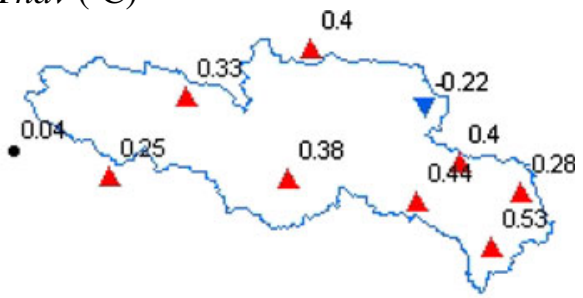

$\operatorname{Tnfd}(\mathrm{d})$
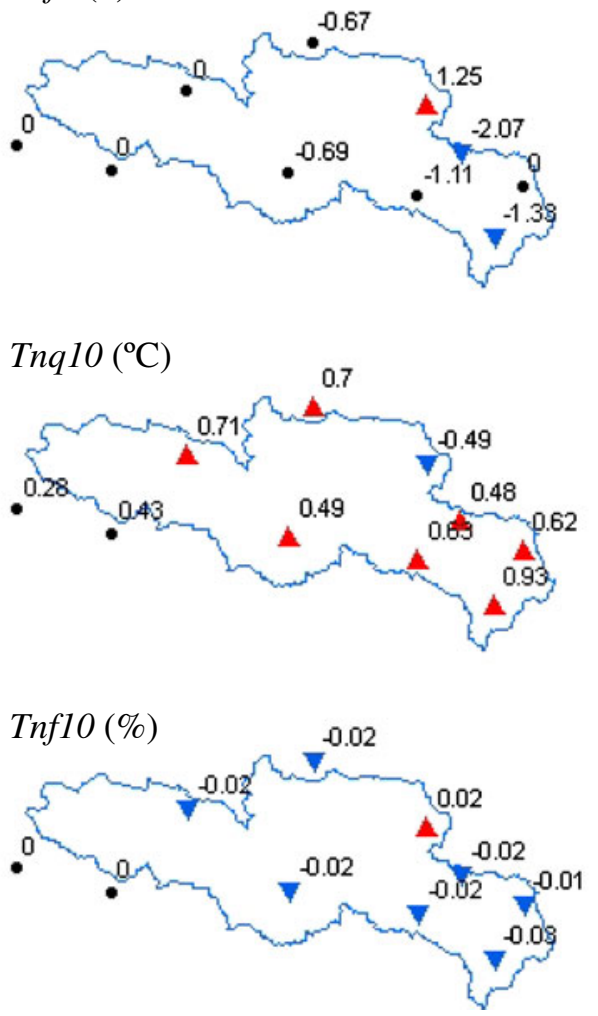

Fig. 4 Same as in Fig. 2, but for spring

(Tnav) shows significant increase in the three periods with the period 1961-2006 having the largest percentage of significant warming trends $(80 \%)$, followed by $1961-$ 1990 and 1961-2000 with 69.2\% and 66.7\%, respectively. The annual pattern of Tnav is very consistent throughout the year with similar proportions of significant positive trends across the different seasons.

A significant decrease has been found in mean diurnal temperature range (Trav) on an annual basis. About $60 \%$ of the stations exhibited a significant downward trend for the three periods. Spring has the largest proportion of stations (70-77\%) showing a significant decrease in the three periods, followed by winter with about $53-60 \%$ of the stations showing a significant downward trend. During summer and autumn, 

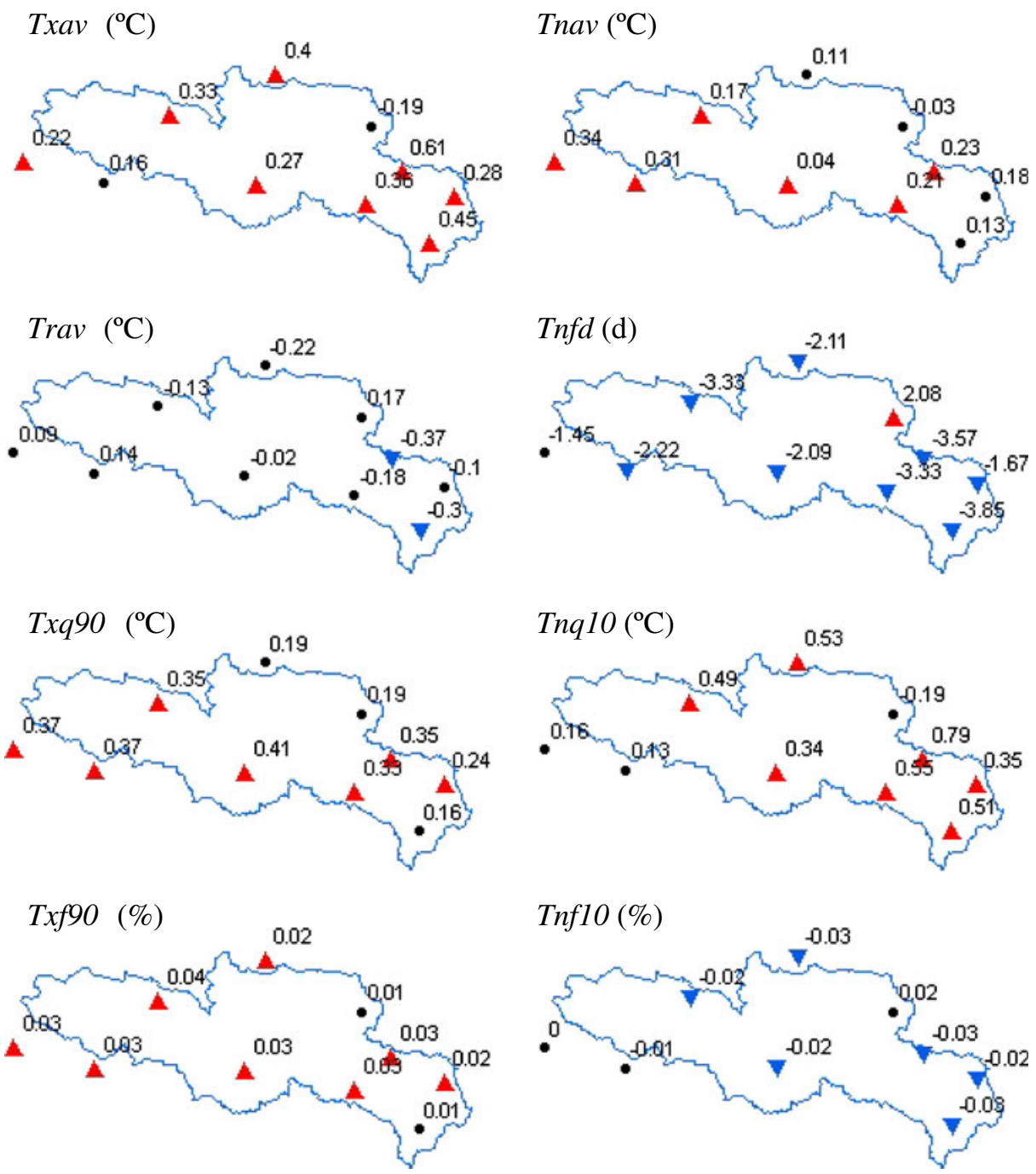

Fig. 5 Same as in Fig. 2, but for summer

the majority of the stations remain stationary, and only few of the stations show significant trends. The number of frost days $(T n f d)$ has significantly declined in the three periods. The period 1961-2006 has the largest number of the stations $(70 \%)$ showing a significant decline while there is less percentage of the stations (23 and $33 \%$, respectively) with significant negative trends for the periods 1961-1990 and 1961-2000. The largest decline occurs in summer with $80 \%$ of the stations showing significant decline in the period 1961-2006. However, no significant change has been detected at the majority of stations in the other seasons.

Significant increasing trends also dominate in $T x q 90$ on annual basis during the period 1961-2006 with $40 \%$ of the stations showing a significant positive trend, 

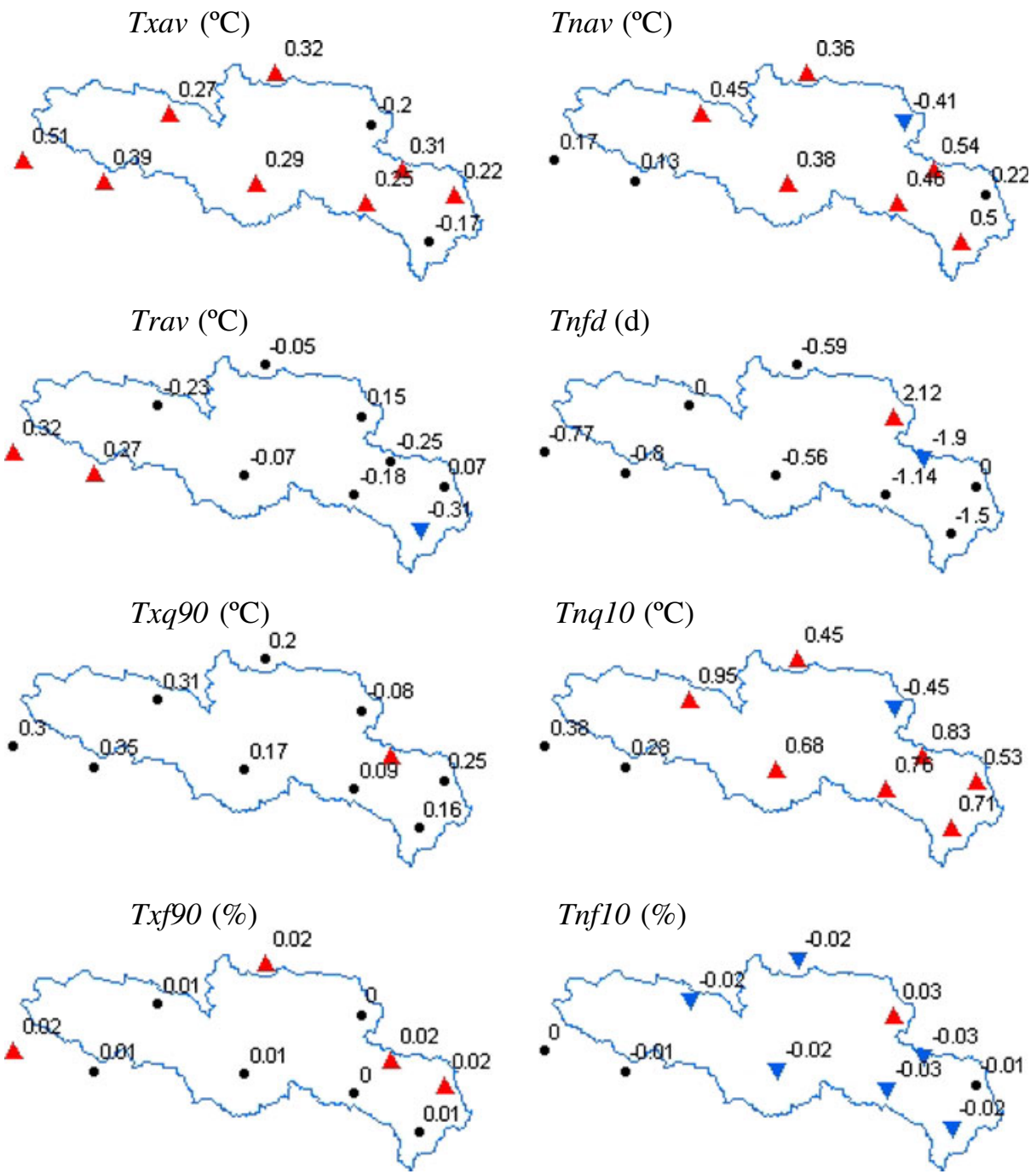

Fig. 6 Same as in Fig. 2, but for autumn

whereas no significant changes are noted for the other two periods. On a seasonal analysis, summer has the largest number of stations (25\% and $70 \%$, respectively) showing a significant upward trend for the two periods 1961-2000 and 1961-2006. Winter follows with $25-40 \%$ of the stations having significant positive trends for the three periods. Spring and autumn shows an insignificant change. For Tnq10, significant increase has been detected at about $50-70 \%$ of the stations in the three periods. The pattern is consistent throughout the year.

On an annual basis, there are a large number of stations with increasing trends for $T x f 90$ over the period 1961-2006, with as many as $70 \%$ of the stations reach significance while no significant change was noted for the two shorter periods. Summer 

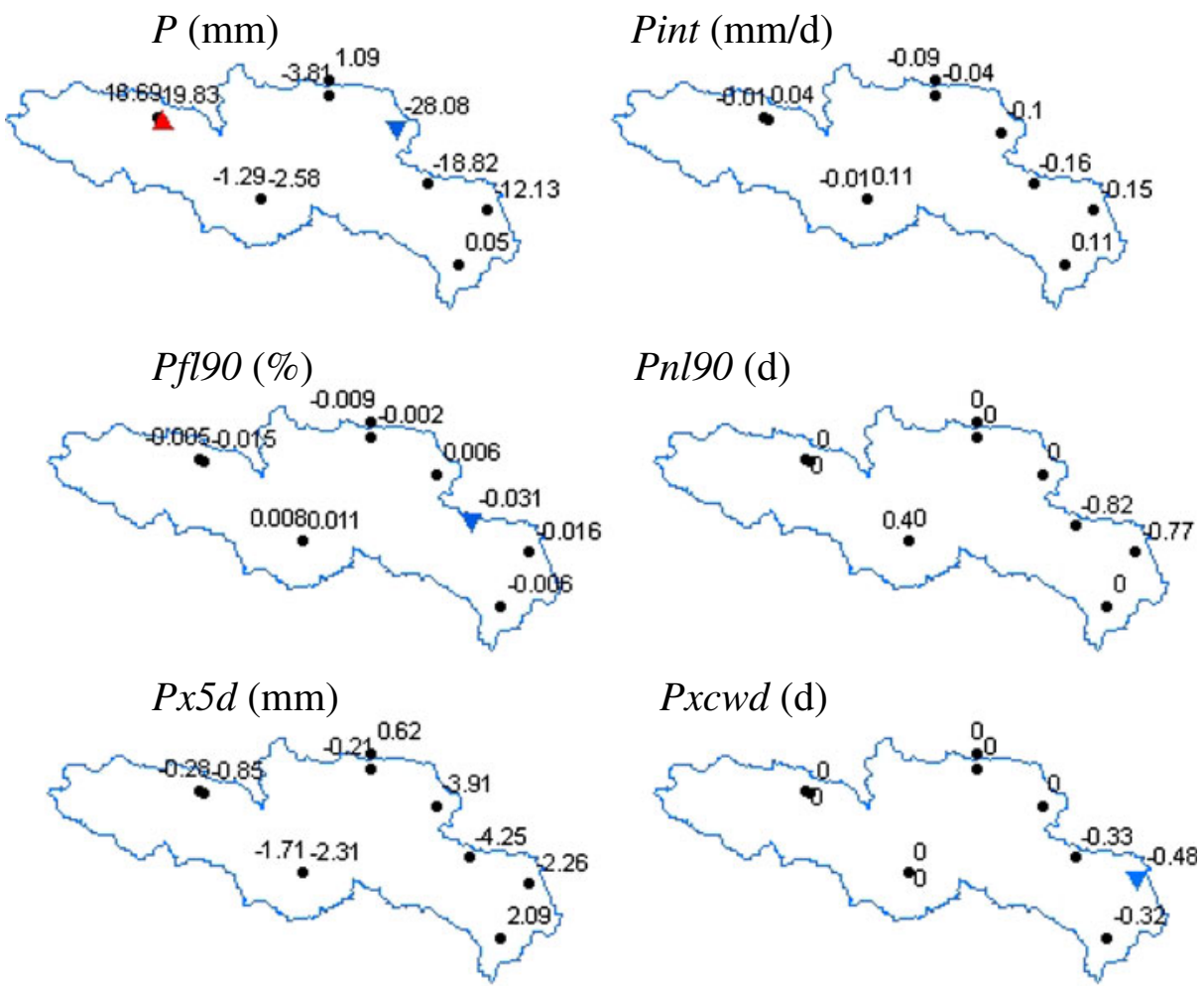

$\operatorname{Pxcwd}(\mathrm{d})$

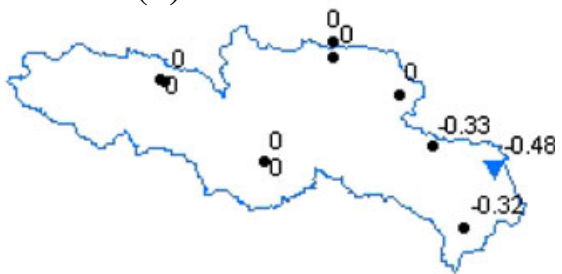

$\operatorname{Pxc} d d(\mathrm{~d})$

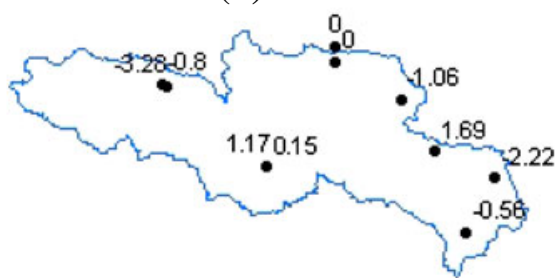

Fig. 7 Signs of trends and change per decade for the seven annual rainfall indices in the study area for the period 1960-2000. Significant increasing (decreasing) trends are marked by filled triangles (filled upright triangle, filled inverse triangle). Insignificant trends are marked by small dots (filled circle)

has the largest number of stations (70\%) showing significant increasing trends in the period 1961-2006 while there are less (33\%) or even no stations with significant positive trends in the periods 1961-2000 and 1961-1990, respectively. Similarly, a significant increase also dominate in winter and autumn with about $40 \%$ of the stations showing significant positive trends over the period 1961-2006 while spring shows insignificant changes. In contrast, Tnf10 is dominated by a significant decrease in the three periods with $60-80 \%$ of the stations having significant negative trends. The annual pattern of Tnf10 is very similar and consistent throughout the different seasons. 

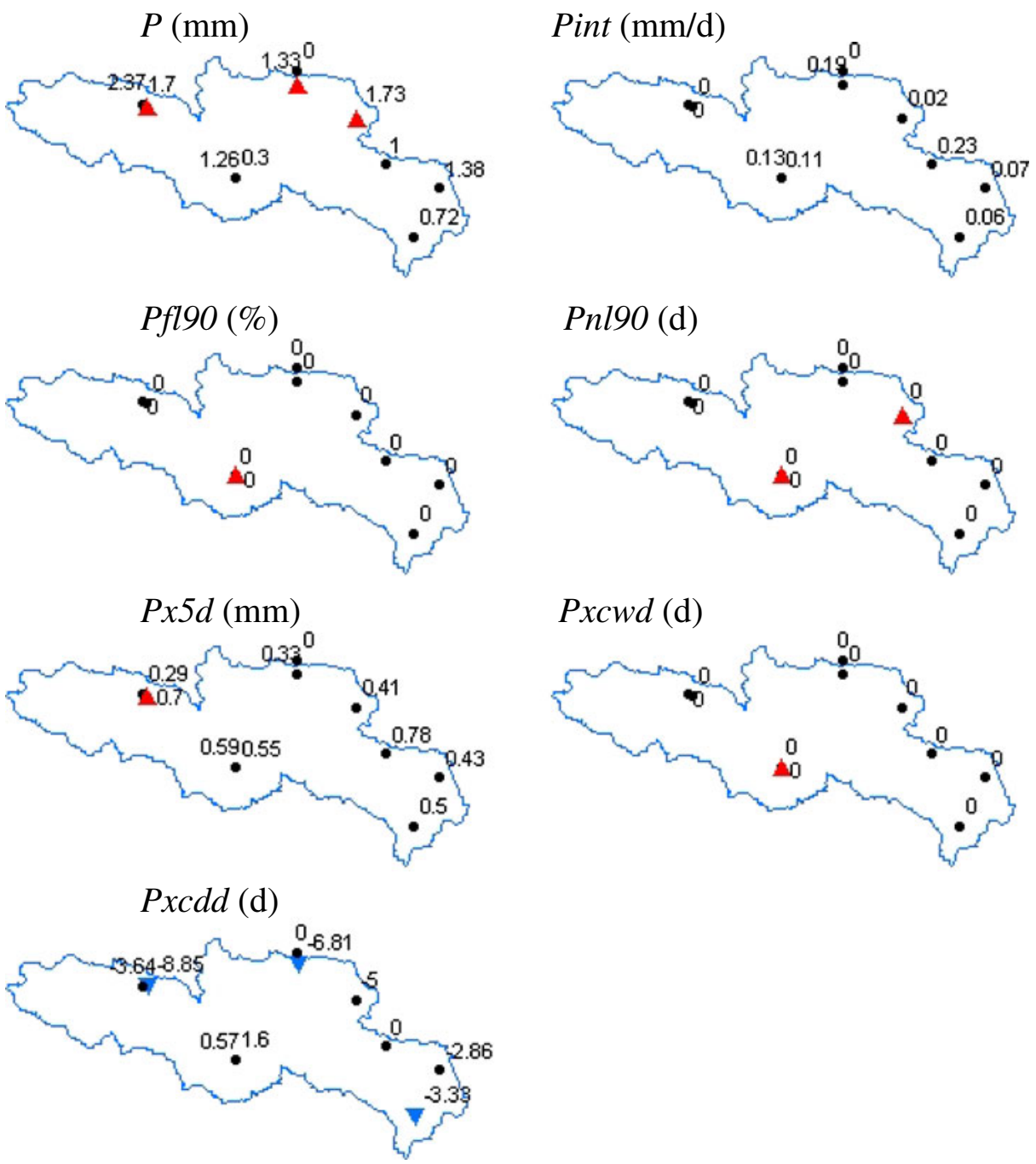

Fig. 8 Same as in Fig. 7, but for winter

\subsection{Rainfall}

In contrast to the temperature indices, there are no significant changes in all the rainfall indices over the study region for the three study periods. This is indicated by no significant trends being detected at $70-100 \%$ of the stations. Trends in the two longer periods (1960-2000 and 1960-2006) are more consistent and pronounced than the shorter period (1960-1990). Although in the majority of the stations no significant trends have been detected for the seven rainfall indices, some seasonal and spatial differences are noticed.

No significant changes are noted in annual rainfall total $(P)$ for the three periods except in the upper part of the study region where $P$ has significantly increased at a 

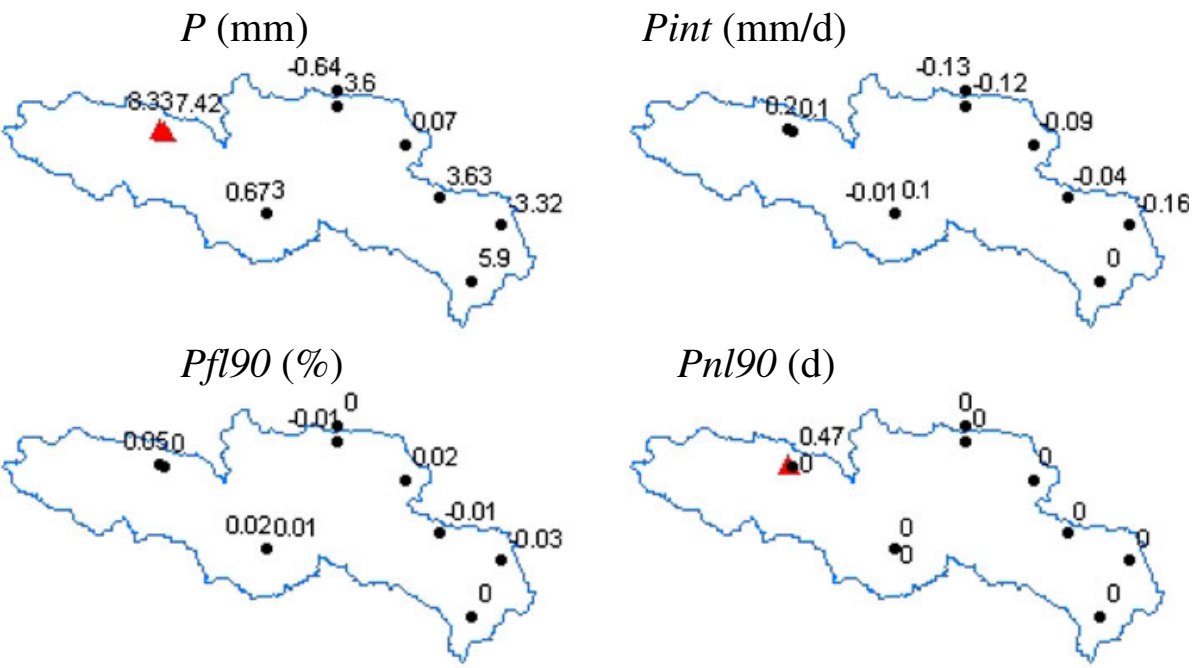

$\operatorname{Pnl90}$ (d)
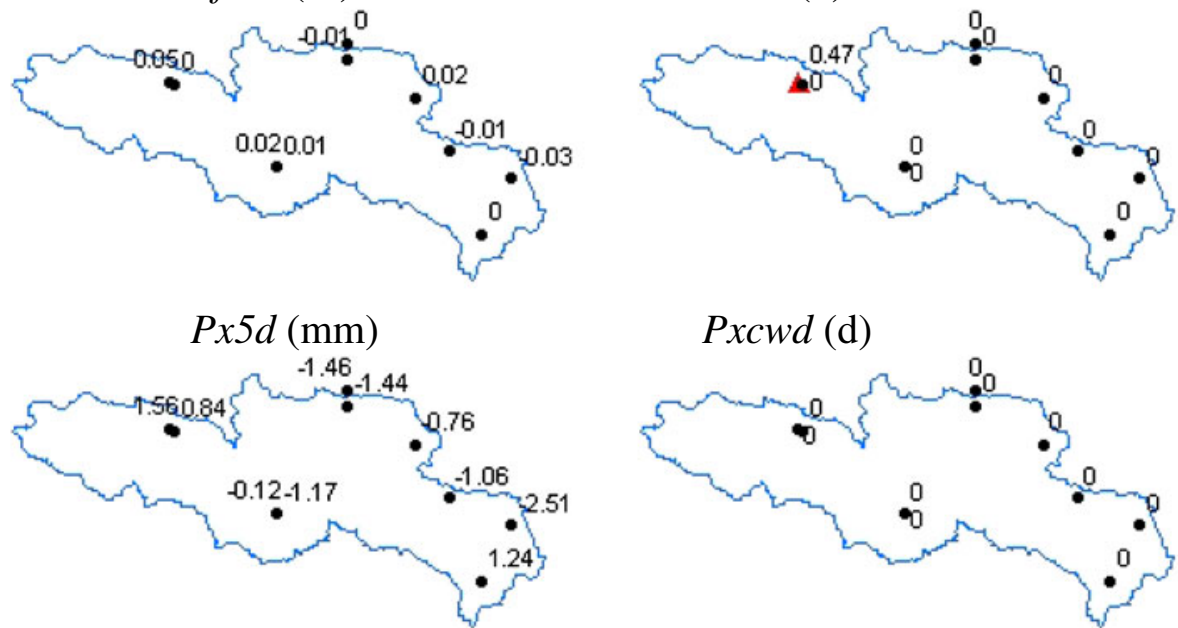

Pxcwd (d)

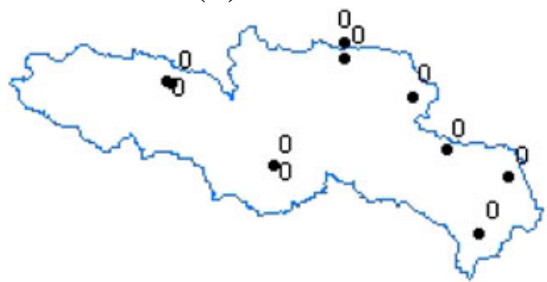

Pxcdd (d)

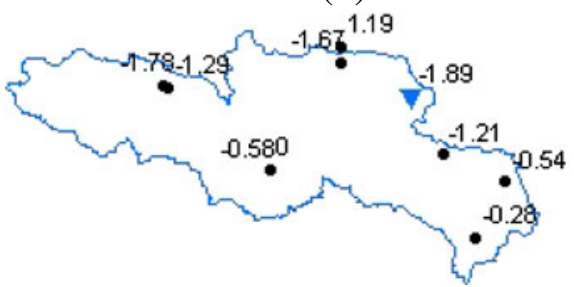

Fig. 9 Same as in Fig. 7, but for spring

rate of $19.83 \mathrm{~mm} /$ decade. Insignificant change in annual rainfall is also reported by Zhao et al. (2007) and Xu et al. (2007) for the Yellow River source region over the period 1960-2000. Winter has the largest proportion of stations (about 28.6-30\%) showing a significant increase in $P$, followed by spring with $7.1-28.6 \%$ of stations showing a significant positive trend. As in the annual basis, $P$ shows a significant increasing trend in winter and spring in the upper part of the study region. In contrast, $14.3-20 \%$ of stations exhibit significant decrease in $P$ in autumn while all stations show no significant change in summer. The mean precipitation per wet day (Pint) is characterized on an annual basis by no significant trends being detected at all stations. The annual pattern of Pint is consistent throughout the different seasons. 

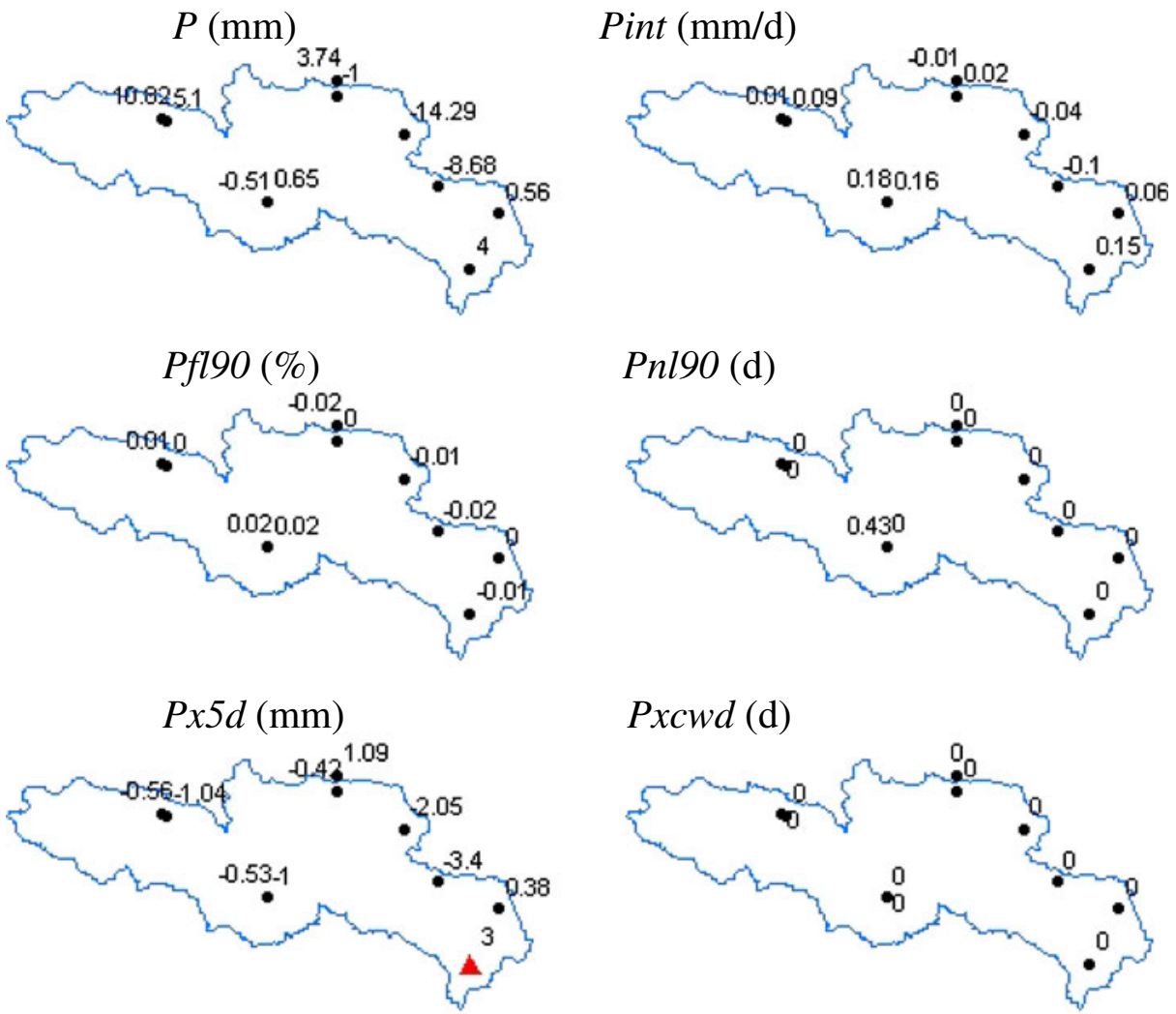

Pxcwd (d)
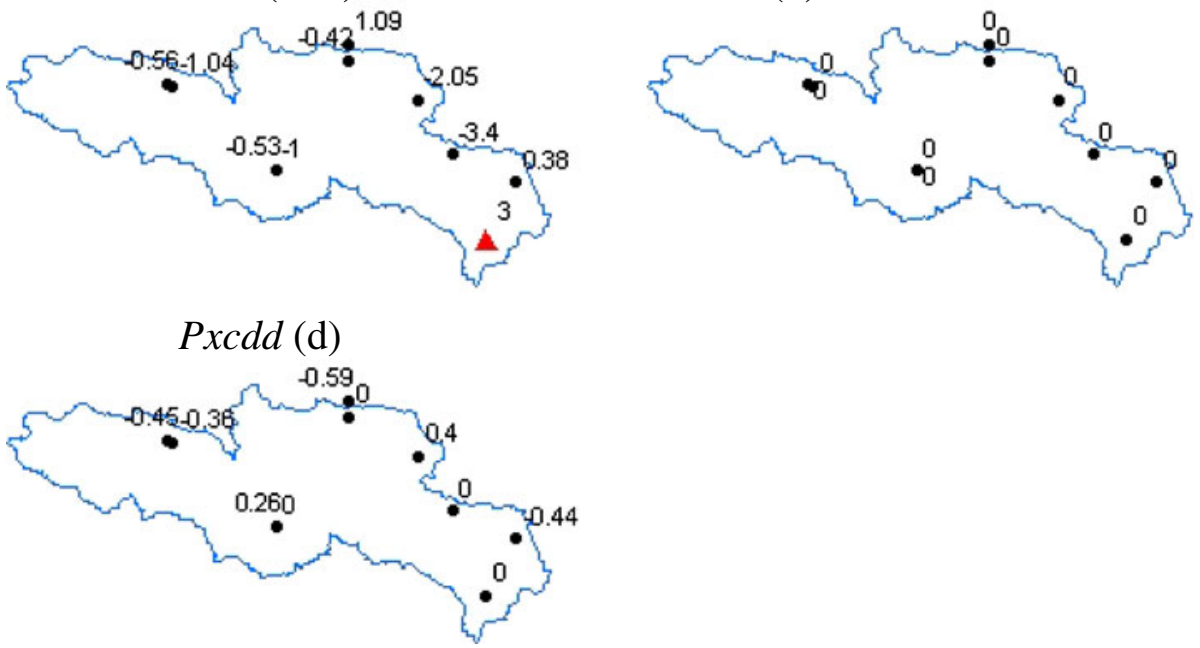

Fig. 10 Same as in Fig. 7, but for summer

At the majority of stations ( $85.7 \%$ of the stations) no significant trends were found in $P f l 90$ for the three periods on both annual and seasonal basis. Similarly, the number of events exceeding the long-term 90th percentile of precipitation ( $P$ nl90) also shows no significant trends at the majority of stations $(80 \%)$. The index of accumulated rainfall during the 5 days with heaviest rainfall $(P x 5 d)$ is related to the most intense rainfall events. On annual basis, $P x 5 d$ tends to be stationary at all stations. In winter, significant increase in Px5d occurs in the upper part of the study region, whereas $20 \%$ of the stations, mainly in the lower part of the study region, show significant decrease in autumn. 

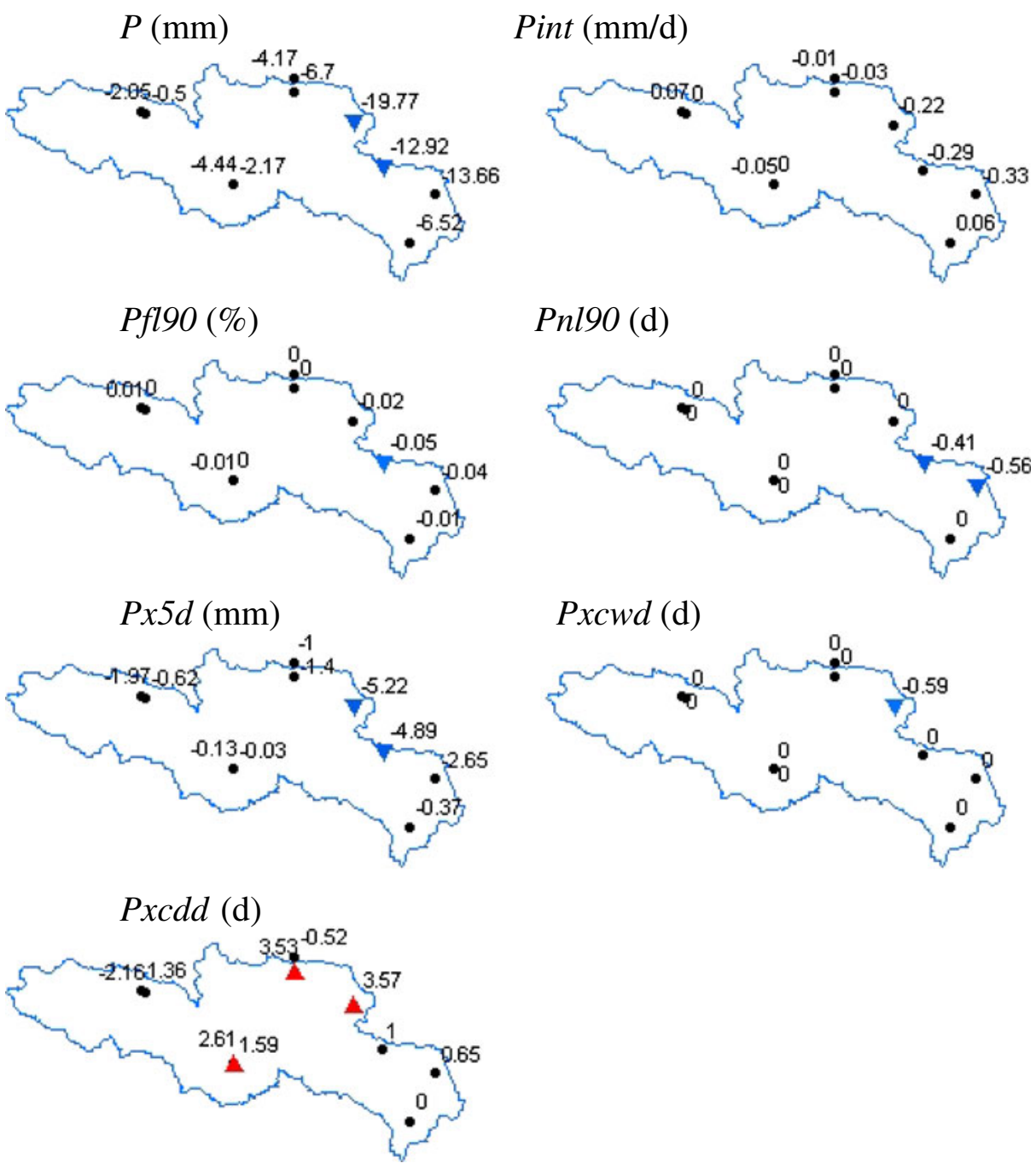

Fig. 11 Same as in Fig. 7, but for autumn

Almost all stations show no significant trends in the length of wet periods ( $P x c w d)$ on annual basis. The annual pattern is consistent throughout the different seasons. Although no clear pattern is found for Pxcdd on annual basis, some seasonal differences are noticed. 7.1-30\% of the stations exhibit significant decreasing trend in winter and spring while $14.3-30 \%$ show significant increasing trend in autumn.

\subsection{Regional average index series}

To obtain a general picture of changes in the temperature and rainfall indices over the whole study area, the trend test is also carried out for the regional average index series. Table 5 presents the trend test results for regionally averaged indices for 
Table 5 Mann-Kendall statistics for regional average indices series

\begin{tabular}{|c|c|c|c|c|c|}
\hline & $\mathrm{DJF}$ & MAM & JJA & SON & Annual \\
\hline \multicolumn{6}{|c|}{ Temperature indices } \\
\hline Txav & 1.75 & 0.13 & 2.63 & 3.07 & 2.94 \\
\hline Tnav & 3.84 & 4.69 & 3.83 & 2.73 & 5.15 \\
\hline Trav & -2.00 & -3.12 & -1.11 & -0.89 & -2.42 \\
\hline Tnfd & 0.13 & -0.49 & -4.10 & -0.53 & -2.91 \\
\hline Txq90 & 2.63 & 0.51 & 2.78 & 0.89 & 1.83 \\
\hline Tnq10 & 2.76 & 3.23 & 4.32 & 4.16 & 4.39 \\
\hline$T x f 90$ & 2.31 & 0.44 & 3.57 & 2.37 & 3.62 \\
\hline Tnf10 & -3.19 & -3.59 & -4.15 & -3.38 & -4.95 \\
\hline \multicolumn{6}{|c|}{ Rainfall indices } \\
\hline$P x 5 d$ & 2.01 & -0.31 & -0.87 & -0.79 & -0.89 \\
\hline Pxcdd & -0.15 & -1.71 & 0.24 & 0.73 & -1.12 \\
\hline Pxcwd & 1.60 & 1.22 & -1.44 & -0.77 & -1.48 \\
\hline Pint & 0.30 & -2.16 & -0.81 & -1.02 & -2.03 \\
\hline Pfl9o & 0.07 & -1.82 & -1.90 & -1.10 & -2.07 \\
\hline Pnl90 & 0.36 & -0.71 & -1.90 & -1.34 & -1.62 \\
\hline$P$ & 2.70 & 1.91 & -0.50 & -1.12 & -0.29 \\
\hline
\end{tabular}

Numbers rendered in italics indicate significance at the $10 \%$ level

the period 1960-2006. The time series of annual region averaged temperature and rainfall indices can be seen in Figs. 12 and 13, respectively.

\subsubsection{Temperature}

On annual basis, significant trends dominate all the regionally averaged temperature indices. Out of eight indices, five (Txav, Tnav, Txq90, Tnq10 and Txf90) show a significant upward trend while the remaining three (Trav, Tnfd and Tnf10) show a significant downward trend. In winter, all the indices show a significant trend except Tnfd with no significant change. Both Trav and Tnf10 exhibit a significant downward trend while the remaining five indices show a significant upward trend. In comparison to winter, spring has less number of indices with significant trends. Tnav and Tnq10 show a significant upward trend while Trav and Tnf10 show a significant downward trend. In summer, all the indices show a significant trend except Trav. Tnfd and Tnf10 show a significant downward trend while the contrast occurs for the remaining indices. In autumn, four indices (Txav, Tnav, Txq90 and Tnq10) show a significant upward trend, and one index (Tnf10) shows a significant downward trend. In spite of some seasonal differences, it is noticeable that throughout the year both Tnav and Tnq10 show a significant upward trend while Tnf10 shows a significant downward trend. This indicated that significant warming occurs in the minimum temperature related indices throughout the year.

\subsubsection{Rainfall}

On annual basis, both the rainfall intensity (Pint) and the contribution of moderately heavy rainfall events to total $P(P f l 90)$ show a significant decreasing trend, whereas no significant changes are found for the remaining indices. Seasonal precipitation shows a significant increasing trend in winter, which is accompanied by a significant increasing trend in the maximum 5-d rainfall $(P x 5 d)$. In spring, there is a significant 
a. Txav

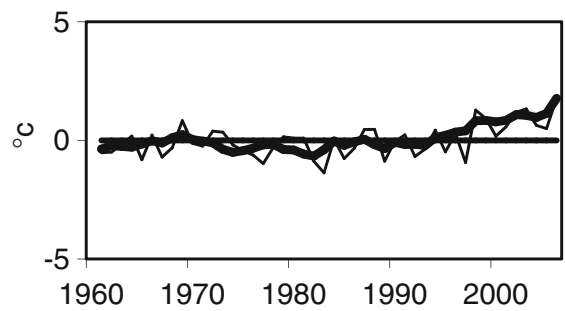

c. Trav

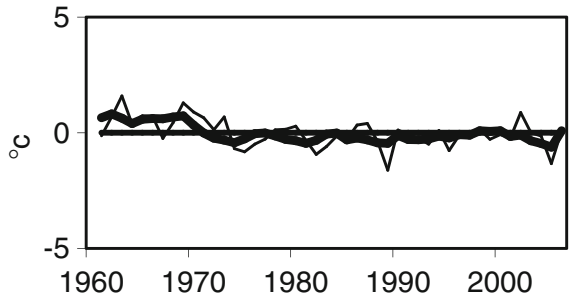

e. $T x q 90$

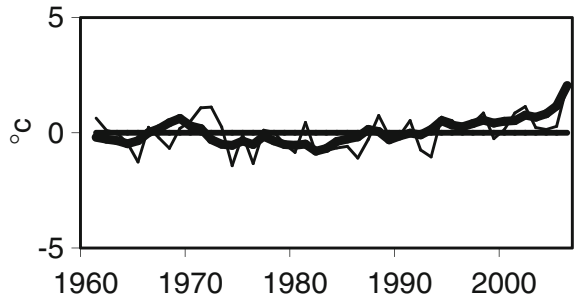

g. $T \times f 90$

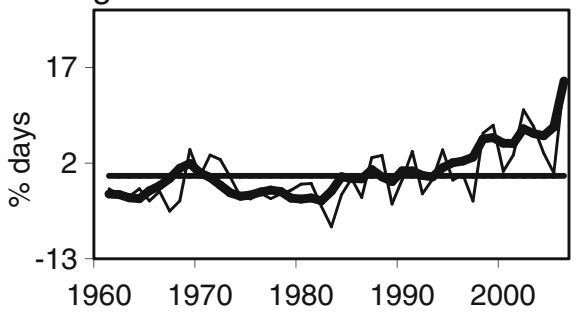

b. Tnav

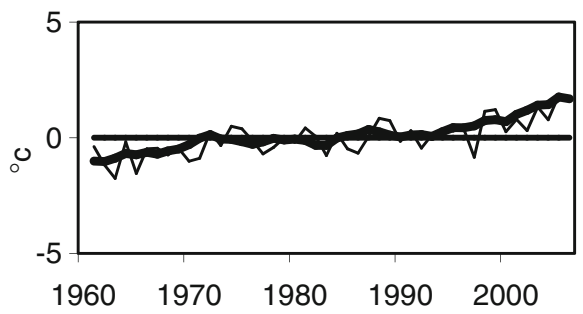

d. Tnfd

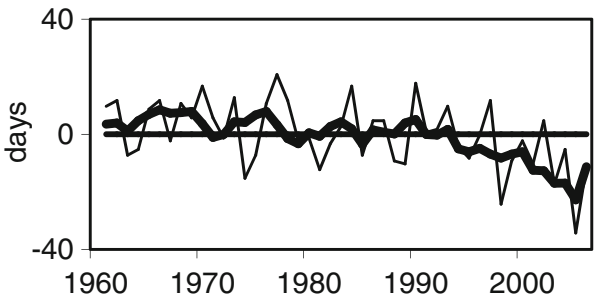

f. Tnq 10

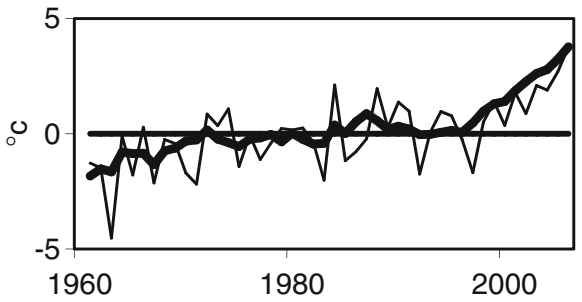

h. Tnf10

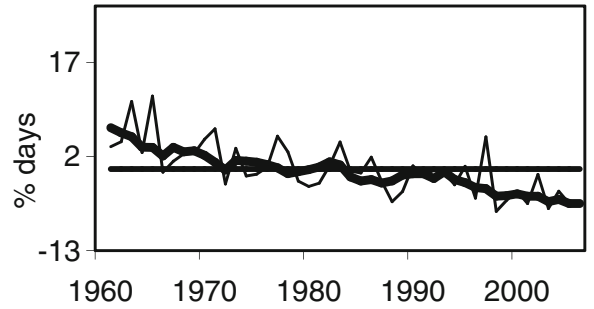

Fig. 12 Time series for annual region averaged temperature indices. Thin curves show the regional average. Thick curves show 5 years moving average. Horizontal lines show the 1961-2006 average. Data are plotted as anomalies from the 1961-2006 average

increasing trend in precipitation $(P)$ and a significant decreasing trend in the duration of dry spells $($ Pxcdd), rainfall intensity (Pint) and the contribution of moderately heavy rainfall events to total $P(P f l 90)$. A significant decreasing trend in the frequency and contribution of moderately heavy rainfall events to total $P$ ( $P f l 90$, $P n l 90)$ is observed in summer. However, none of the indices show significant trends in autumn. 


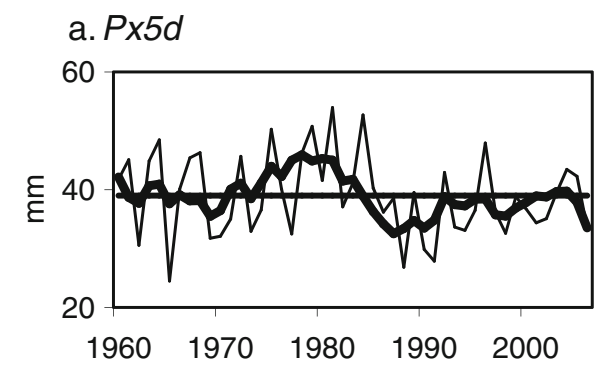

b. Pint

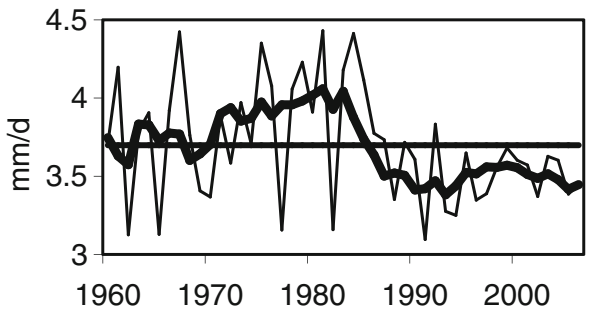

\section{c. Pxcwd}

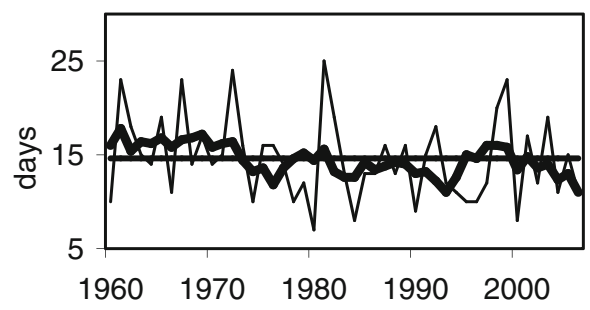

d. Pxcdd

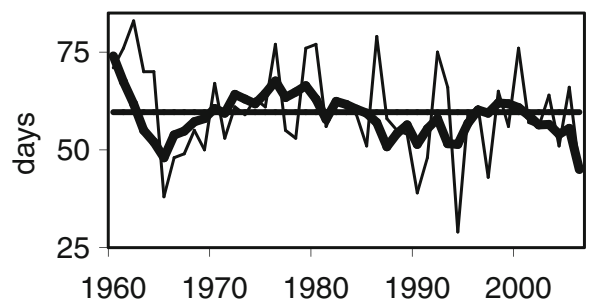

e. Pn190

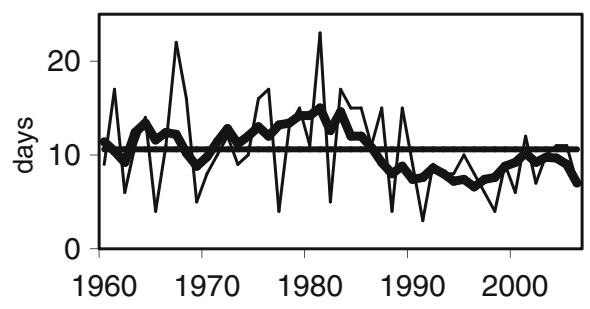

f. Pfl90
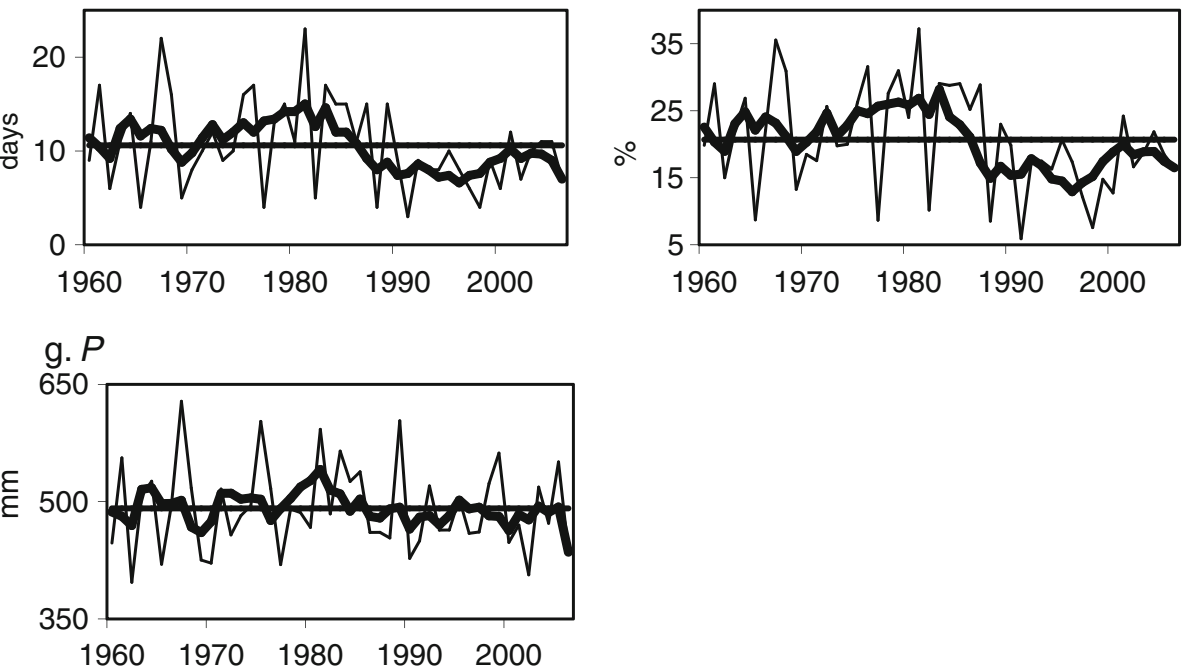

Fig. 13 Time series for annual region averaged rainfall indices. Thin curves show the regional average. Thick curves show 5 years moving average. Horizontal lines show the 1960-2006 average

\section{Discussion and conclusions}

In this study we analyzed spatio-temporal changes in a set of daily rainfall and temperature indices on both annual and seasonal basis for the Yellow River source region over the three periods: 1960-1990, 1960-2000 and 1960-2006. Changes in the daily data values and spatio-temporal distribution of rainfall and temperature have 
important implications for water supply in the whole basin that is mainly limited by the water availability in this region.

Significant warming trends dominate the study region over the second half of the twentieth century as a whole. The warming in the study region mainly results from significant increase in winter minimum temperature. This finding is in agreement with results for the whole Yellow River basin (Fu et al. 2004; Zhang et al. 2008). Furthermore, increase in the minimum temperature is much larger than that in the maximum temperature, which results in significant reduction in the diurnal temperature range over most of the region except in the west part of the region where the contrast occurs. This reduction is particularly strong in winter with some stations having trends as much as a $0.5 \sim 0.7^{\circ} \mathrm{C}$ decade $^{-1}$ decrease. The reduction in the diurnal temperature range over most of this region is also reported by Tang et al. (2008) for the period 1960-2000. This is consistent with the trend in the global diurnal temperature range (Easterling et al. 1997). There is a widespread decrease in the number of annual frost days with the largest reduction in summer. On annual basis, the frequency and magnitude of hot events show an upward trend over most of the region with some notable seasonal differences. For example, summer shows the largest increase in both the frequency and magnitude of hot events, with winter to follow, whereas spring and autumn show no significant change. Compared to the annual pattern in the hot events, changes in the magnitude and the frequency of cold events is very consistent throughout the year, e.g. the magnitude of the cold events has significantly increased while the frequency showed a decreasing trend. Zhang et al. (2008) also indicated that the upper reach of the Yellow River is characterized by a significant upward trend of frequency of extreme hot events and by a significant downward trend of frequency of extreme cold events.

Changes in all the indices are spatially coherent for all the stations except for Henan station located in the eastern part of study, which consistently shows opposite trends compared to other stations. Similar findings for the mean air temperature have been reported by Zhao et al. (2007) and Xu et al. (2007). They also found the mean air temperature has decreased in the area around Henan station. This behaviour may indicate large climate variability in the mountainous region. However, this hypothesis has not yet been verified. Although changes are spatially coherent for most indices, the rate of change varied, e.g. changes in the cold indices for the western region is much smaller than that for the rest parts of region while the contrast occurs in the warm indices.

Although most stations across the study area did not show any significant changes in the rainfall indices, some noticeable changes were observed for the regionally averaged indices: (a) On annual basis, there is a significant decline in average rainfall intensity and contribution of moderately heavy rainfall events to total $P$ across the study area. (b) Winter rainfall has generally increased significantly, which is accompanied by a significant increase in Px5d. (c) Spring rainfall is also found to have a significant increasing trend, which is accompanied by a significant decline in the number of dry days, average rainfall intensity and contribution of moderately heavy rainfall events to total $P$. (d) Both the frequency and contribution of moderately heavy rainfall events to total $P$ has significantly decreased in summer.

The results of this study indicate that the climate in the Yellow River source region has become warmer and experienced some seasonally varying changes in rainfall, which is in agreement with the conclusions by Niu et al. (2004) for the northeastern 
Tibetan Plateau. In addition, it partly supports an emerging global picture of warming and prevailing positive trends in rainfall extremes over the mid-latitudinal land areas of the Northern Hemisphere in winter. However, this study is based on relatively short periods (40-45 year) and rather sparse station coverage. Thus, it is unclear as to whether these trends are part of a longer period of oscillation or the result of long term climate change.

Acknowledgements This study was jointly supported by UNESCO-IHE Institute for Water Education, Rijkswaterstaat (the Ministry of Transport, Public Works and Water Management), Netherlands and Yellow River Conservancy Commission, China. Special thanks go to Dr. Y. W. Jia and Dr. H. L. Zhao (China Institute of Water Resources and Hydropower Research) for provision of the data set used in this study.

\section{References}

Beniston M (2003) Climatic change in mountain regions: a review of possible impacts. Clim Change 59:5-31

Beniston M, Diaz HF, Bradley RS (1997) Climatic change at high elevation sites: an overview. Clim Change 36:233-251

Brunetti M, Buffoni L, Maugeri M, Nanni T (2000) Precipitation intensity trends in northern Italy. Int J Climatol 20:1017-1031

Brunetti M, Maugeri M, Nanni T (2001) Changes in total precipitation, rainy days and extreme events in northeastern Italy. Int J Climatol 21:861-871

Easterling DR, Horton B, Jones PD, Peterson TC, Karl TR, Parker DE, Salinger MJ, Razuvayev V, Plummer N, Jamason P, Folland CK (1997) Maximum and minimum temperature trends for the globe. Sci 277:364-367

Fu GB, Chen SL, Liu CM, Shepard D (2004) Hydro-climatic trends of the Yellow River basin for the last 50 years. Clim Change 65:149-178

Groisman PY, Knight RW, Easterling DR, Karl TR, Hegerl GC, Razuvaev VAN (2005) Trends in intense precipitation in the climate record. J Climate 18:1326-1350

Haylock M, Goodess C (2004) Interannual variability of European extreme winter rainfall and links with mean large-scale circulation. Int J Climatol 24:759-776

Haylock M, Nicholls N (2000) Trends in extreme rainfall indices for an updated high quality data set for Australia, 1910-1998. Int J Climatol 20:1533-1541

Hundecha Y, Bardossy A (2005) Trends in daily precipitation and temperature extremes across western Germany in the second half of the 20th century. Int J Climatol 25:1189-1202

Katz RW, Brown BG (1992) Extreme events in a changing climate: variability is more important than averages. Clim Change 21:289-302

Kendall MG (1975) Rank correlation measures. Charles Griffin, London

Kruger AC (2006) Observed trends in daily precipitation indices in South Africa: 1910-2004. Int J Climatol 26:2275-2285

Kundzewicz ZW, Ulbrich U, Brucher T, Graczyk D, Kruger A, Leckebusch GC, Menzel L, Pinskwar I, Radziejewski M, Szwed M (2005) Summer floods in central Europe-climate change track? Nat Hazards 36:165-189

Kunkel KE, Andsager K, Easterling DR (1999) Long-term trends in extreme precipitation events over coterminous United States and Canada. J Climate 12:2515-527

Kyselý J (2008) Trends in heavy precipitation in the Czech Republic over 1961-2005. Int J Climatol 29:1745-1758. doi:10.1002/joc.1784

Liu X, Chen B (2000) Climatic warming in the Tibetan plateau during recent decades. Int J Climatol 20:1729-1742

López-Moreno J, Vicente-Serrano S, Angulo-Martínez M, Beguería S, Kenawy A (2009) Trends in daily precipitation on the northeastern Iberian Peninsula, 1955-2006. Int J Climatol 30:10261041. doi:10.1002/joc. 1945

Mann HB (1945) Non-parametric tests against trend. Econometrica 13:245-259 
Manton MJ, Della-Marta PM, Haylock MR, Hennessy KJ, Nicholls N, Chambers LE, Collins DA, Daw G, Finet A, Gunawan D, Inape K, Isobe H, Kestin TS, Lefale P, Leyu CH, Lwin T, Maitrepierre L, Ouprasitwong N, Page CM, Pahalad J, Plummer N, Salinger MJ, Suppiah R, Tran VL, Trewin B, Tibig I, Yee D (2001) Trends in extreme daily rainfall and temperature in Southeast Asia and the South Pacific: 1961-1998. Int J Climatol 21:269-284

Masih I, Uhlenbrook S, Maskey S, Smakhtin V (2010) Streamflow trends and climate linkages in the Zagros Mountains, Iran. Clim Change 104:317-338. doi:10.1007/s10584-009-9793-x

Michaels PJ, Knappenberg PC, Fraunfeld OW, Davis RE (2004) Trends in precipitation on the wettest days of the year across contiguous USA. Int J Climatol 24:1873-1882

Mirza MMQ (2003) Climate change and extreme weather events: can developing countries adapt? Climate Policy 3:233-248

Moberg A, Jones PD (2005) Trends in indices for extremes in daily temperature and precipitation in central and western Europe, 1901-99. Int J Climatol 25:1149-1171

Nandintsetseg B, Greene S, Goulden CE (2007) Trends in extreme daily precipitation and temperature near Lake Hövsgöl. Int J Climatol 27:341-347

Niu T, Chen LX, Zhou ZJ (2004) The characteristics of climate change over the Tibetan plateau in the last 40 years and the detection of climatic jumps. Adv Atmos Sci 21(2):193-203

Osborn TJ, Hulme M, Jones PD, Basnett TA (2000) Observed trends in the daily intensity of United Kingdom precipitation. Int J Climatol 20:347-364

Plummer N, Salinger MJ, Nicholls N, Suppiah R, Hennessy KJ, Leighton RM, Trewin B, Page CM, Lough JM (1999) Changes in climate extremes over the Australian region and New Zealand during the twentieth century. Clim Change 42:183-202

Ramos MC, Martinez-Cassanovas JA (2006) Trends in precipitation concentration and extremes in the Mediterranean Penédes-Anoia Region, NE Spain. Clim Change 74:457-474

Salinger MJ, Griffiths GM (2001) Trends in New Zealand daily temperature and rainfall extremes. Int J Climatol 21:1437-1452

Sato Y, Ma XY, Xu JQ, Matsuoka M, Zheng HX, Liu CM and Fukushima Y (2008) Analysis of long-term water balance in the source area of the Yellow River basin. Hydrol Process 22:16181629

Schmidli J, Frei C (2005) Trends of heavy precipitation and wet and dry spells in Switzerland during the 20th century. Int J Climatol 25:753-771

Sen PK (1968) Estimates of the regression coefficient based on Kendall's tau. J Am Stat Assoc 63:1379-1389

Sen Roy S, Balling RC (2004) Trends in extreme daily precipitation indices in India. Int J Climatol 24:457-466

Suppiah R, Hennessy KJ (1998) Trends in total rainfall, heavy rain events and number of dry days in Australia, 1910-1990. Int J Climatol 10:1141-1164

Tang Q, Oki T, Kanae S, Hu H (2008) A spatial analysis of hydro-climatic and vegetation condition trends in the Yellow River basin. Hydrol Process 22:451-458

Ulbrich U, Brücher T, Fink AH, Leckebusch GC, Krüger A, Pinto JG (2003) The central European floods of August 2002. Part I: rainfall periods and flood development. Weather 58: 371-377

Vincent LA, Mekis E (2006) Changes in daily and extreme temperature and precipitation indices for Canada over the twentieth century. Atmos-Ocean 44:177-193

von Storch H, Navarra A (eds) (1995) Analysis of climate variability. Springer, New York.

Wagner D (1996) Scenarios of extreme temperature events. Clim Change 33:385-407

Wang G, Qian J, Cheng G, Lai Y (2001) Eco-environmental degradation and causal analysis in the source region of the Yellow River. Environ Geol 40:884-890

Wang W, Chen X, Shi P, and van Gelder PHAJM (2008) Detecting changes in extreme precipitation and extreme streamflow in the Dongjiang River Basin in southern China. Hydrol Earth Syst Sci 12:207-221

Xu ZX, Li JY, Liu CM (2007) Long-term trend analysis for major climate variables in the Yellow River Basin. Hydrol Process 21:1935-1948

Yang D, Li C, Hu H, Lei Z, Yang S, Kusuda T, Koike T, Musiake K (2004) Analysis of water resources variability in the Yellow River of China during the last half century using historic data. Water Resour Res 40:W06502. doi:10.1029/2003WR002763

Zhai P, Pan X (2003) Trends in temperature extremes during 1951-1999 in China. Geophys Res Lett 30(17):1913. doi:10.1029/2003GL018004

Zhai P, Sun A, Ren F, Liu X, Gao B, Zhang Q (1999) Changes of climate extremes in China. Clim Change 42:203-218 
Zhai P, Zhang X, Wan H, and Pan X (2005) Trends in total precipitation and frequency of daily precipitation extremes over China. J Climate 18(6):1096-1107

Zhang X, Hogg WD, Mekis E (2001) Spatial and temporal characteristics of heavy precipitation events over Canada. J Climate 14:1923-1936

Zhang X, Zwiers FW, Li G (2004) Monte Carlo experiments on the detection of trends in extreme values. J Climate 17:1945-1952

Zhang Q, Xu CY, Zhang Z, Ren G, Chen YD (2008) Climate change or variability? The case of Yellow river as indicated by extreme maximum and minimum air temperature during 1960-2004. Theor Appl Climatol 93:35-43

Zhao FF, Xu ZX and Huang JX (2007) Long-term trend and abrupt change for major climate variables in the upper Yellow River Basin. Acta Meteorol Sin 21(2):204-214

Zheng HX, Zhang L, Liu CM, Shao QX, Fukushima Y (2007) Changes in stream flow regime in headwater catchments of the Yellow River basin since the 1950s. Hydrol Process 21:886-893 